\title{
Techno-economic evolution of an existing operational NGL plant with adding LNG production part
}

\author{
Omid Sabbagh ${ }^{1}$, Mohammad Ali Fanaei ${ }^{1, *}$, and Alireza Arjomand ${ }^{2}$ \\ ${ }^{1}$ Department of Chemical Engineering, Ferdowsi University of Mashhad, 9177948974 Mashhad, Iran \\ ${ }^{2}$ Faculty of Chemical and Materials Engineering, Shahrood University of Technology, 3619995161 Shahrood, Iran
}

Received: 1 February 2020 / Accepted: 12 March 2020

\begin{abstract}
Natural gas is the fastest-growing fossil fuel and LNG is playing a growing role in the world's gas supply. The liquefaction process is also by far the most energy-consuming part of the LNG chain. It is thus a priority today for the gas industry to decrease the cost and improve the efficiency of the liquefaction process of a plant. In this way, a novel techno-economic evolution of an existing NGL plant with adding an appropriate LNG production part is presented. Concerning the availability of propane, use of existing equipments and conditions of no structural changes in the existing installation, C3MR is used as the refrigeration system. For full recognition of the process, a high-accuracy surrogate model based on D-optimal approach is developed. MR composition (nitrogen, methane, ethane, and propane), inlet gas pressure of the LNG production part, demethanizer pressure, and high and low pressure of MR as the eight manipulated variables of the surrogate model predict the earned profit of the integrated plant. To increase profit, a hybrid GA-SQP optimization method is used. The results show that the earned profit of the optimized proposed plant with the LNG production capacity of $3.33 \mathrm{MTPA}$ is $60.2 \%$ more than the existing NGL plant. In addition to increased earned profit, the thermodynamic efficiency is improved in the liquefaction section, too. Furthermore, the SPC value of $0.347 \mathrm{kWh} \mathrm{kg}^{-1}$ LNG shows that the optimized plant has acceptable liquefaction efficiency. According to the optimization results, mixture variables are more effective than process variables on the earned profit. It is noticeable that increasing the ethane recovery not always increases profit in such integrated units.
\end{abstract}

\section{Nomenclature}

$\begin{array}{ll}\text { AR } & \text { Annualized Revenue, } \$ \text { year }^{-1} \\ \text { BM } & \text { Bare-Module Cost, } \$ \\ C_{\text {buildings }} & \text { Building costs, } \$ \\ C_{\text {equipment }} & \text { Equipment cost, } \$ \\ C_{\text {install }} & \text { Installed cost, } \$ \\ C_{\text {site }} & \text { Site preparation cost, } \$ \\ C_{\mathrm{WC}} & \text { Working capital cost, } \$ \\ \text { EP } & \text { Earned Profit, } \$ \text { year } \\ \text { IAR } & \text { Increased Annualized Revenue, } \$ \text { year }^{-1} \\ \text { IEC } & \text { Increased Electricity Cost, } \$ \text { year } \\ \text { ISC } & \text { Increased Steam Cost, } \$ \text { year } \\ \text { MTA } & \text { Minimum Temperature Approach, }{ }^{\circ} \mathrm{C} \\ \text { SPC } & \text { Specific Power Energy Consumption, } \\ & \mathrm{kWh} \mathrm{kg}^{-1} \text { LNG } \\ \text { TIAC } & \text { Total Increased Annualized Cost, } \$ \text { year }\end{array}$

* Corresponding author: fanaei@um.ac.ir $\begin{array}{ll}\text { TIBM } & \text { Total Increased Bare-Module Investment, } \$ \\ \text { TICI } & \text { Total Increased Capital Investment, } \$ \text { year }^{-1} \\ \text { TIOC } & \text { Total Increased Operating Cost, } \$ \text { year }^{-1} \\ x_{i} & \text { Manipulated variables }\end{array}$

Abbreviations

ANOVA Analysis Of Variance

APEA Aspen Process Economic Analyzer ${ }^{\circledR}$

AP-SMR Air Products' Single Mixed Refrigerant

ARS Absorption Refrigeration System

C3MR Propane Precooled Mixed Refrigerant

CNG Compressed Natural Gas

DMR Double Mixed Refrigerant

DOF Degree of Freedom

EDR Exchanger Design and Rating

GA Genetic Algorithm

KBO Knowledge-Based Optimization

KSMR Korea Single Mixed Refrigerant 


$\begin{array}{ll}\text { LNG } & \text { Liquefied Natural Gas } \\ \text { MFC } & \text { Mixed Fluid Cascade } \\ \text { MR } & \text { Mixed Refrigerant } \\ \text { MTPA } & \text { Million Tons Per Annum } \\ \text { NG } & \text { Natural Gas } \\ \text { NGL } & \text { Natural Gas Liquids } \\ \text { NRU } & \text { Nitrogen Rejection Unit } \\ \text { OCLP } & \text { ConocoPhillips Optimized Cascade LNG } \\ & \text { Process } \\ \text { SMR } & \text { Single Mixed Refrigerant } \\ \text { SQP } & \text { Sequential Quadratic Programming }\end{array}$

\section{Introduction}

Natural gas plays a growing role in the energy mix by displacing coal due to its relative economic and/or environmental advantages in some markets. Today, its share in the energy mix is $23 \%$, compared to $21 \%$ in 2010 [1]. NG is used as a combustible for every consuming sector (power generation, industry, and buildings) excepted transport. It is also increasingly utilized as a feedstock for industry, especially petrochemicals, thanks to the growing developments of high-liquids fields in the US and Middle East. After extracting natural gas, it must be transported to different places for each of its various applications. There are three main technological options for this work: transmission through pipeline, LNG, and CNG. Each of these methods has its applications, but this investigation focused on the LNG. Liquefaction of natural gas is the most dynamic sector of the gas industry. It is playing a fast growing role in the gas supply, driving the expansion and globalization of gas markets. LNG should in particular overtake pipeline gas to become the most important way of trading gas over long distance by the late 2020s. Long distance LNG trade is forecast to grow $5 \% /$ year in the next decade, compared to only $1 \%$ year for pipeline gas. Nowadays, more than $30 \%$ of the worldwide gas trading is done via LNG [2].

The cost of pipeline transportation varies roughly linearly with the distance, while the LNG technology is little dependent. LNG is more economical to transport to long-distance than an onshore high-pressure pipeline, over $3500 \mathrm{~km}$, when a new greenfield LNG project (rather than a brownfield project) is considered [3]. There are different technologies for liquefying natural gas, in onshore facilities, that can be classified into three general categories. Mixed refrigerant based methods such as SMR, KSMR, AP-SMR, C3MR, and DMR place in the first category. These processes have higher thermal efficiency, because of avoiding the difference of temperatures between the enthalpic profiles of MR and NG, and less equipment will be required. But reliability and operations of the processes are more sensitive against the pure refrigerant systems and need more accurate design $[4,5]$. Using MRs in small plants with respect to increasing the capital cost are less desirable [6]. In the second category, methods such as OCLP and MFC utilize a cascade of pure or mixed refrigerants for NG liquefaction. The pure refrigerant cascade processes like OCLP, usually use methane, ethylene, and propane as refrigerants. These processes in one hand have a simple operation with high reliability and loss of one train does not cause the plant shutdown. On the other hand, the cascade processes require relatively high capital and maintenance costs due to the amount of equipment needed for the refrigerant cycle. Therefore, the pure refrigerant cascade processes are suitable for large-capacity trains. The MR cascade processes like MFC can obtain a closer matching of MR warming and NG cooling curves inside heat exchangers, so display better thermal efficiency in compared to the pure refrigerant cascade processes, but these technologies are very sensitive to changing NG composition [5, 7-9]. Finally, the third category included hybrid processes such as Liquefin and AP-X, combine two or more NG liquefaction technologies with the aim of higher operating efficiency and lower operating cost. The main problem in using these methods is the lack of operational experience.

Due to the extensive nature of NG liquefaction processes, whether in terms of energy or equipment cost, a few improvements can be highly valuable. Accordingly, in recent years many efforts have been made to optimize the processes. Shirazi and Mowla [10], Khan et al. [7], Khan and Lee [11], Moein et al. [12], and Lee and Moon [13] simulated an SMR cryogenic cycle for producing LNG. They successfully improved efficiency of the process by decreasing the compression energy requirement. In this way, different optimization methods such as GA, nonlinear programming, and particle swarm paradigm were utilized. Alabdulkarem et al. [14] studied on a C3MR plant with a large number of variables. They reduced the complexity of the GA optimization problem by carrying it out in two stages. First, $\mathrm{MR}$ and then the propane cycle were optimized. The results showed that optimization decreased the power consumption near $9.08 \%$. Wang et al. $[15,16]$ performed a thermodynamic analysis based study of the minimization of the energy consumption of a C3MR process. Their optimization results by applying an SQP and nonlinear programming algorithm indicated that energy savings can be around 13\%. Hwang et al. [17] determined the optimal operating conditions for the DMR cycle by considering power efficiency. These conditions obtained from the mathematical model formulated by using a hybrid optimization method consisting of the GA and SQP. As a result, the required power at the obtained conditions decreased by $34.5 \%$ compared with the conditions obtained from the used patent. Sanavandi and Ziabasharhagh [18] modeled a three-stage propane precooling cycle. In this study, the minimization of specific energy consumption has been defined as the main objective function. MR composition has been recognized as the most effective parameter on the performance of the cycle. Therefore, MR composition has been optimized by two methods; HYSYS optimizer functions and sensitivity analysis of MR composition. The specific energy consumption at a sustainable optimized condition decreased $5.35 \%$. Khan et al. [19] developed the DMR process liquefaction followed by its optimization using Box methodology and controlled elitist GA. They optimized this process by 
minimizing specific compression energy and overall heat transfer coefficient (UA). There existed a partial trade-off between the objective functions, thus a multi-objective optimization performed that results in a simultaneous decreased of $24 \%$ and $3 \%$ in the specific compression energy and UA values. Sun et al. [20] simulated the AP-X process and optimized it by decreasing the power consumption with GA. The optimized unit power consumption was $15.56 \%$ less than of the base case. Ding et al. [21] simulated the MFC process and analyzed the effects of different parameters on the unit power consumption. Their optimization results with GA indicated the reduction power consumption by $4.655 \mathrm{kWh} \mathrm{kmol}^{-1}$. Nawaz et al. optimized the MFC process by reducing the exergy losses. According to their results overall exergy losses can be minimized to $34.4 \%$ that made $25.4 \%$ energy savings compared to base MFC processes [22]. He et al. studied on a modified SMR and nitrogen expansion processes. They optimized the processes by minimizing specific energy consumption and total investment. Then the exergy efficiency and capability of handling different feed gas conditions for liquefaction of mentioned processes were comprised. Their results showed that the modified SMR had a lower specific energy consumption, higher exergy efficiency, lower total investment, and higher flexibility than the nitrogen expansion process [23].

In recent years, some studies have evaluated the effects of integration of NGL/LNG and NGL/LNG/NRU processes. The reasons for this issue are due to the low operating temperature and existence of some identical equipments in the mentioned processes that introduce them as series plants. It is also necessary to express that when the content of nitrogen in the natural gas is more than $4 \%$ (mole fraction); its separation is economically feasible. Vatani et al. [24] introduced and analyzed a novel integrated process configuration for NGL/LNG production that included two MR cycles. SPC and ethane recovery in the process are $0.414 \mathrm{kWh} \mathrm{kg}^{-1}$ LNG and higher than $93.3 \%$ respectively. He and $\mathrm{Ju}[25]$ proposed and optimized another novel integrated process for the small-scale LNG plant. Their results showed that the energy consumption and flow rate of the MRs can be reduced by $9.64 \%$ and $11.68 \%$ compared with the base case respectively. This study is also one of the few articles in the field of NGL/ LNG integration that has done economic analysis. The analysis indicated that the proposed process demonstrates good profitability and a short payback period. Khan et al. [26] presented three configurations of the NGL/LNG integration process with using the developed KSMR cycle. They compared the configurations in the aspect of the amount of energy consumption. Then the best case optimized for the compression energy requirement by varying the refrigerant composition and operating pressure levels with a KBO methodology. The results demonstrated that in the optimal case, the amount of SPC is equal to $0.3863 \mathrm{kWh} \mathrm{kg}^{-1}$ LNG and the compression energy requirement is decreased by $9 \%$ compared to the base case. Mehrpooya et al. [27] introduced and analyzed three novel process configurations for the integration of NGL and LNG based on C3MR, DMR, and MFC. The results indicated that these integrated processes have high ethane recovery and low SPC $\left(0.391,0.375\right.$ and $0.364 \mathrm{kWh} \mathrm{kg}^{-1}$ LNG, respectively). Uwitonze et al. [28] presented new integrated schemes based on the DMR process which the main highlight of them is splitting of demethanizer into rectifying and stripping sections. They optimized these processes by varying the refrigerant composition and operating pressure levels through KBO methodology. The results demonstrated that the scheme with a fully thermally coupled distillation column has the lowest energy consumption. Ghorbani et al. [29] proposed an NGL/LNG/NRU process based on the C3MR refrigeration system. This integration led to removing reboilers and condensers in demethanizer and denitrogenizer columns. The results showed that the integrated process has SPC of $0.359 \mathrm{kWh} \mathrm{kg}^{-1} \mathrm{LNG}$ and recover NGL more than 90\%. They [4] also designed another integrated process recovery of NGL/LNG/NRU based on MFC by ethane recovery $92 \%$ and SPC $0.343 \mathrm{kWh} \mathrm{kg}^{-1}$ LNG. Finally, they used GA to minimize of SPC and according to the results, reduced it by $6 \%$ $\left(0.3205 \mathrm{kWh} \mathrm{kg}^{-1} \mathrm{LNG}\right)$. Recently, it is evaluated the effect of implementing ARS instead of the precooling stage of C3MR, DMR, and MFC on the reduction of energy consumption. As the results of related studies, using of this method in the NGL/LNG structure in comparison with MFC process and in the NGL/LNG/NRU structure in comparison with C3MR, DMR and MFC processes has reduced the power consumption by about $35.67 \%$, $18.4 \%, 12.6 \%$ and $38.94 \%$, respectively [30-32]. These investigations are listed among the few articles which have been carried out the economic analysis. This is while that according to recent studies, the power consumption is the most commonly selected objective function, considered as a performance indicator, followed by the exergy efficiency.

As mentioned, all of the presented articles in the field of improving the economic efficiency of natural gas liquefaction processes have been based on two overall approaches: optimization of individual LNG processes, and design and optimization of integrated processes. According to the studies, constructing an integrated NGL/LNG unit has more advantages than constructing two individual NGL and LNG units. But what has not been evaluated is the added value resulting from adding an LNG production part to an existing NGL plant. This paper investigated the effect of this integration without applying any structural changes in the current units by examining the earned profit. Another highlighted part of this investigation is concerned with the selection of design variables. Inlet gas pressure of the LNG production part and especially operating pressure of demethanizer column are variables that their optimal values in the integration processes are barely determined. And finally in this article, a surrogate model based on D-optimal approach was used for optimization and full recognition of the process. It should be noted, the reasons of simultaneous studying of the four-member set of NGL plant (dehydration, propane gas refrigeration, ethane recovery and NGL fractionation units) are their impact on hydrocarbons recovery and energy consumption. 


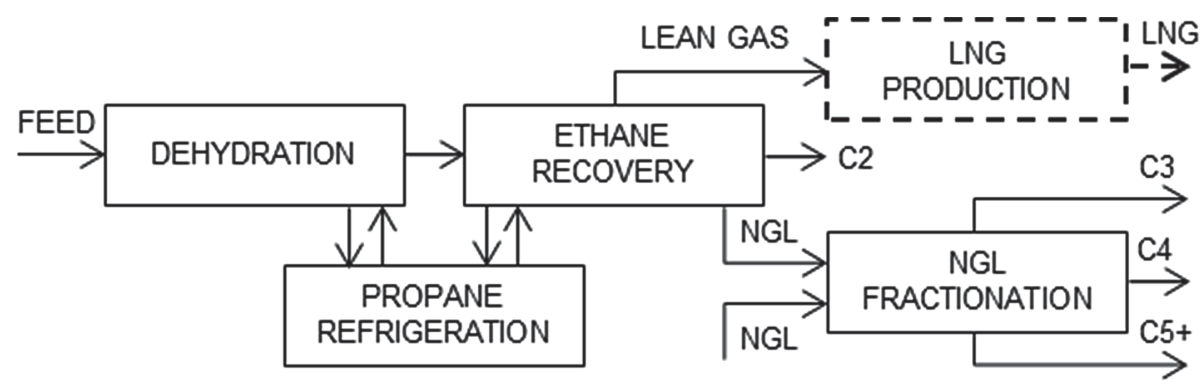

Fig. 1. Block flow diagram of the existing NGL (solid lines) and the integrated NGL/LNG plants.

\section{Process description}

The integrated process is based on the adding LNG production part to the existing NGL plant. As can be seen in Figure 1, the existing plant contains four main units which include dehydration, propane refrigeration, ethane recovery and NGL fractionation (solid lines). However, due to the low operating temperature and existence of the same equipment between this plant and the liquefaction natural gas process, adding an LNG production part is proposed. Figure 1 indicates the block flow diagram of the integrated plant without any structural changes. More details about the process are given in the next sections. Black, blue, pink and green lines in Figures 2 and 3 indicate streams related to NG, propane, MR, and water, respectively.

\subsection{Dehydration unit}

Figure 2a illustrates the schematic of dehydration unit. Natural gas after passing through the pretreatment systems and removing acid gases enters this unit. Table 1 shows the feed gas conditions. Feed gas stream 43 is combined with recycle stream 42 and then is cooled in two stages (104-E101 and 104E-102). Eighty-eight percent of the water content of stream 31 is removed in inlet separator, 104-D101, and the rest of it is eliminated in molecular sieve adsorbent bed, 104-R101. Stream 35 after decreasing pressure, is splitted into two parts. The first part (93\%, stream 36 ), is warmed by LP steam in 104-E103. Finally stream 51, as the feed gas, enters the ethane recovery unit. The remaining $7 \%$ of dried gas, stream 37 , is heated in furnace 104-H101 and used for regeneration of molecular sieve bed. Accordingly, this stream is moistened and therefore after cooling in air cooler 104-A101, enters regeneration gas separator, 104-D102. The current operating conditions of this unit are shown in Table 2.

\subsection{Propane refrigeration unit}

Propane cycle in the existing NGL plant is used for cooling different parts of the dehydration and ethane recovery units. As can be seen in Figure 2b, propane is compressed in two stages compressor, 111-K101A and 111-K101B. The outlet temperature of the first stage is decreased by mixing with stream 148. While outlet stream of the second stage, stream 149, is cooled by heat exchange with air and ethane in 111-A101 and 105-E106, respectively. This stream is divided into two parts and then their pressure decreased. The first part (85\%, stream 142), follows to kettle shell and tube heat exchanger which is modeled by heat exchanger 104-E102 and drum 111-VD101. Stream 143 as the second part follows to 105-E101 and its outlet, stream 257, mixes with vapor outlet of $111-\mathrm{VD} 101$ and then returns to 111-K101B. Liquid outlet of 111-VD101 is splitted into two parts. Part one, containing $33 \%$ of liquid outlet, after decreasing pressure is warmed in 105-E101. The remaining part of the liquid outlet of 111-VD101, stream 144, is used to produce cooling in the condenser of deethanizer column, 105-E105, and then with mixing to stream 146 returns to 111-K101A. The current operating conditions of this unit are shown in Table 2.

\subsection{Ethane recovery and NGL fractionation units}

Figure 2c shows a schematic of the ethane recovery and NGL fractionation units in the existing NGL plant. Stream 51 is directed to a multi-stream heat exchanger, 105-E101, and its temperature decreases to $-35^{\circ} \mathrm{C}$. The outlet stream 52 , flows to separator 105-D101 and its gas product is divided into two parts. The first part (near 30\%) is cooled in 105-E102 and then with decreasing pressure, enters demethanizer column, 105-C101. While another part of the 105-D101 gas product, as same as its liquid product, just after depressurizing enters column 105-C101. According to Table 3, demethanizer column contains 18 theoretical trays, operates at 30 bar and has two liquid side streams. Side streams 249 and 250 are heated in 105-E101 and return to the column. Stream 248, provides required refrigeration in heat exchangers 105-E102, 105-E101, and 104-E101. Stream 57 is compressed in two stages; at first in 105-K101 by using the expander shaft power and then in compressor 106-K101. The compressed lean gas after decreasing temperature in air cooler is sent to pipelines. The bottom product of demethanizer enters deethanizer column, 105-C102, which uses propane as refrigerant of the condenser to achieve high purity of ethane (98 wt.\% without $\mathrm{CO}_{2}$ ). As shown in Table 3, this column has 32 theoretical trays and operates at 30.5 bar. Stream 63 cools propane stream 141 in 105-E106 and the bottom product of deethanizer column is directed to NGL fractionation unit. Stream 64 is depressurized and then is mixed with the same stream that comes from the parallel unit. Stream 


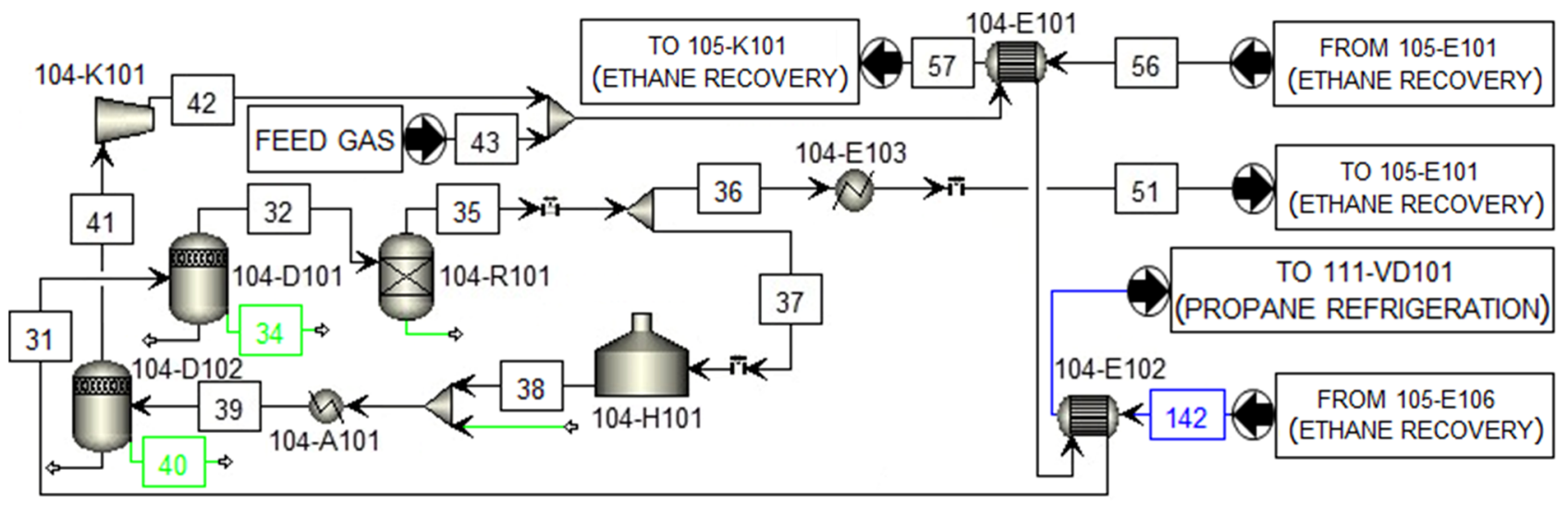

(a)

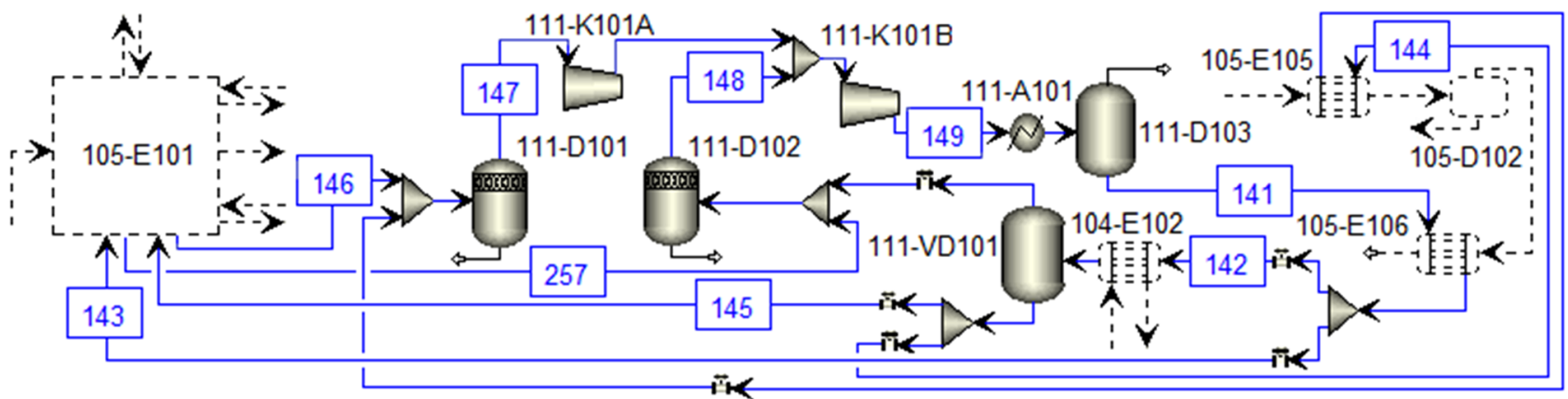

(b)

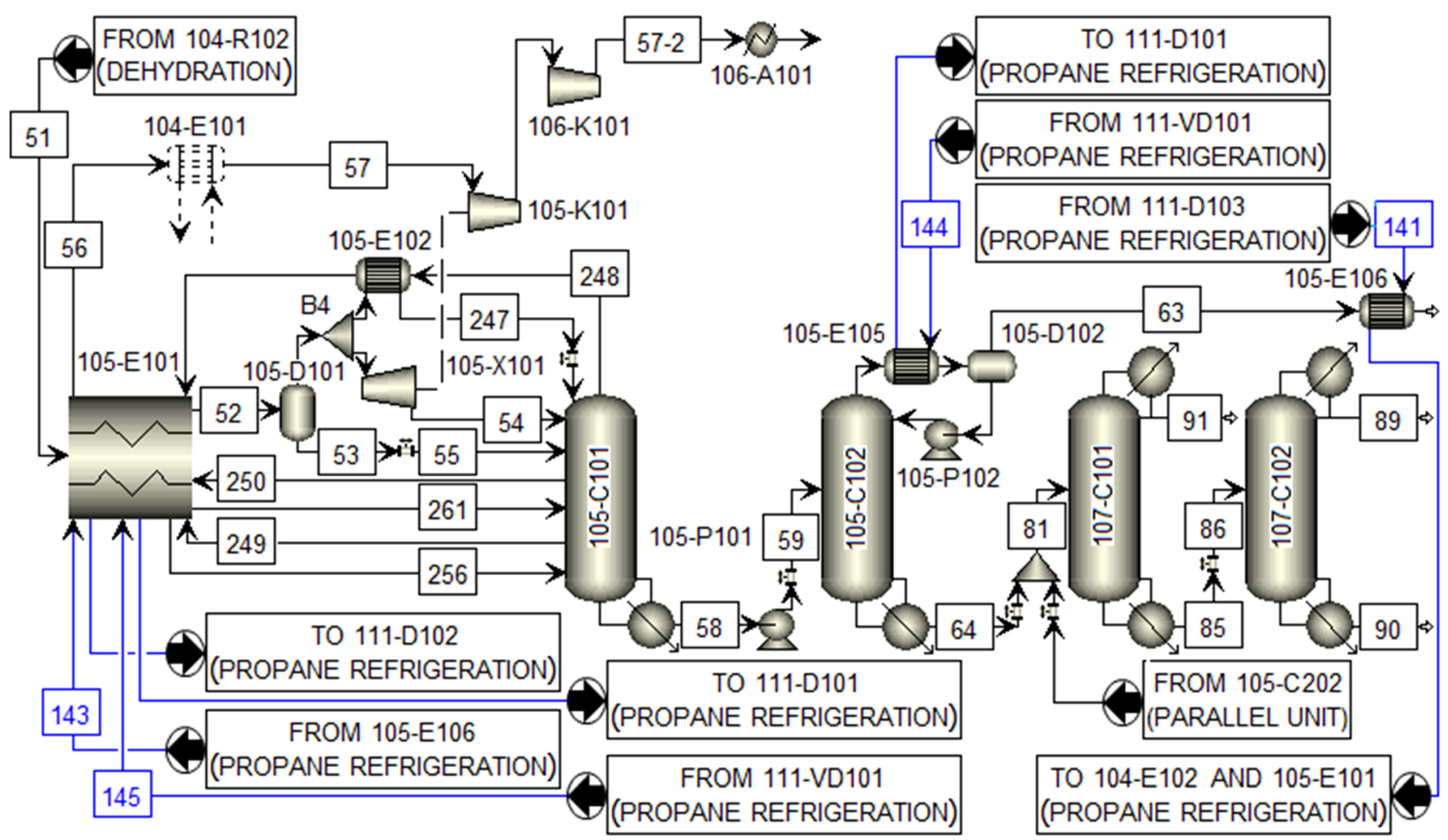

(c)

Fig. 2. Schematic of the existing NGL plant (a) dehydration unit, (b) propane refrigeration unit, (c) ethane recovery and NGL fractionation units. 


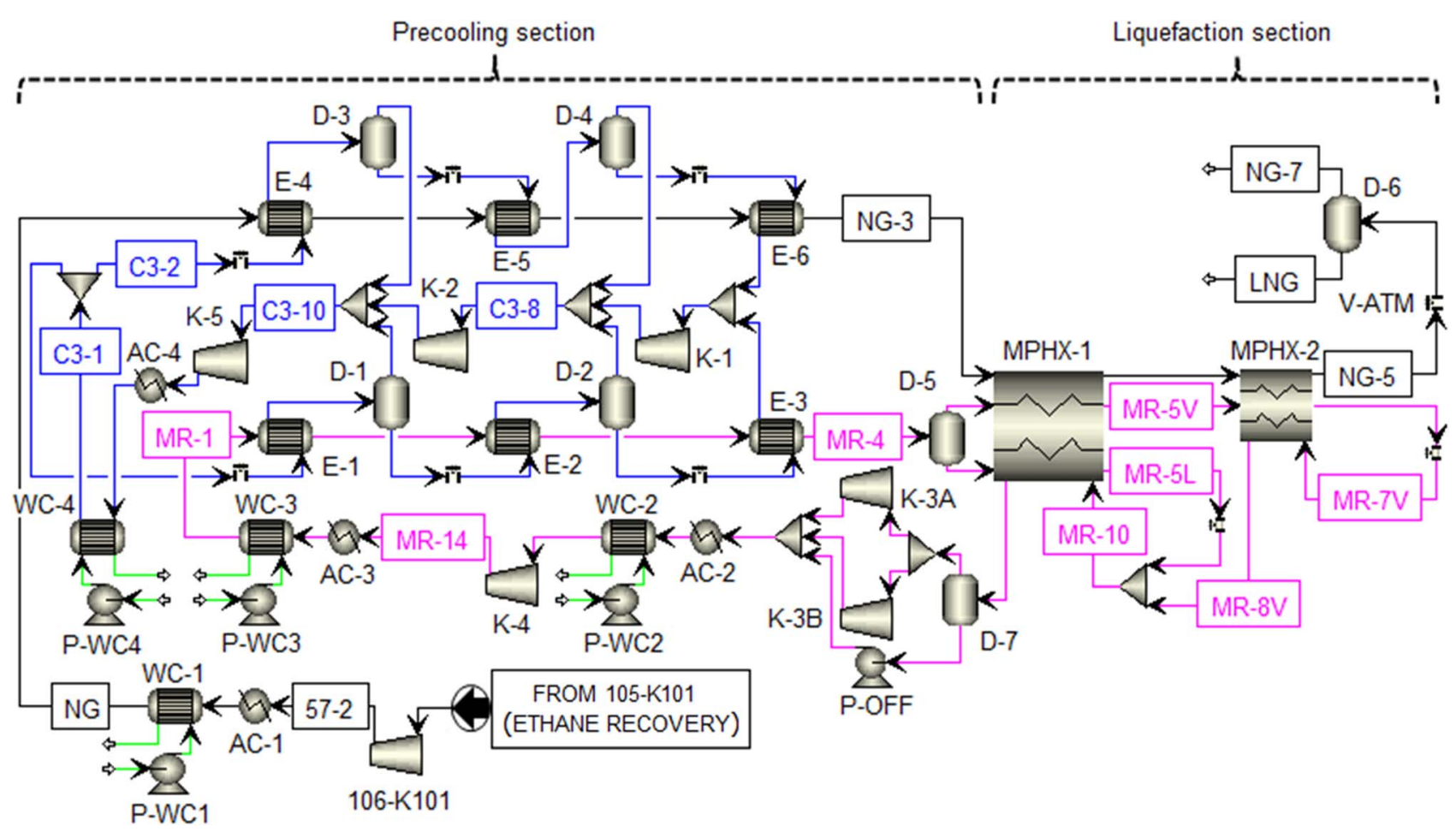

Fig. 3. Schematic of proposed design of LNG production part.

Table 1. Properties of the feed gas.

\begin{tabular}{lc}
\hline Property & Value \\
\hline Temperature $\left({ }^{\circ} \mathrm{C}\right)$ & 44.8 \\
Pressure (bar) & 65.2 \\
Flow $\left(\mathrm{kmol} \mathrm{hr}^{-1}\right)$ & 23849 \\
Composition $(\% \text { mol })^{*}$ & \\
$\mathrm{~N}_{2}$ & 3.53 \\
$\mathrm{CO}_{2}$ & 1.00 \\
$\mathrm{CH}_{4}$ & 86.44 \\
$\mathrm{C}_{2} \mathrm{H}_{6}$ & 5.52 \\
$\mathrm{C}_{3} \mathrm{H}_{8}$ & 2.02 \\
$i-\mathrm{C}_{4} \mathrm{H}_{10}$ & 0.35 \\
$n-\mathrm{C}_{4} \mathrm{H}_{10}$ & 0.52 \\
$i-\mathrm{C}_{5} \mathrm{H}_{12}$ & 0.14 \\
$n-\mathrm{C}_{5} \mathrm{H}_{12}$ & 0.13 \\
$n-\mathrm{C}_{6} \mathrm{H}_{14}$ & 0.10 \\
$n-\mathrm{C}_{7} \mathrm{H}_{16}$ & 0.08 \\
$\mathrm{H}_{2} \mathrm{O}$ & 0.15 \\
\hline${ }^{\mathrm{V}} \mathrm{O}$ &
\end{tabular}

* Very small amounts of $\mathrm{H}_{2} \mathrm{~S}, \mathrm{COS}, \mathrm{CH}_{4} \mathrm{~S}$, and $\mathrm{C}_{2} \mathrm{H}_{6} \mathrm{~S}$ are also present in the feed gas.

81 enters depropanizer column, 107-C101. As shown in Table 3 , this column contains 29 theoretical trays and operates at 22.3 bar. Propane and $\mathrm{C}_{4}{ }^{+}$exit from the top and bottom of depropanizer column. Stream 85 after decreasing pressure enters debutanizer column, 107-C102 which corresponding to Table 3 , contains 27 theoretical trays and operates at 8.2 bar. The current operating conditions of the ethane recovery and NGL fractionation units are shown in Table 2.

\subsection{Added LNG production part}

According to Figures 2c and 3, the top outlet of demethanizer column after providing the required cooling in heat exchangers 105-E102, 105-E101 and 104-E101 and compressed to 75 bar, instead of being sent to pipelines, enters LNG production part. Due to the availability of propane, and condition of no structural changes in the current units, C3MR technology is used for the liquefaction process which has a proven track record in LNG applications worldwide. The existence of precooling stage in this multi-cycle process causes increasing the number of variables and DOFs and hence the difficulty of searching for optimum conditions, compared to a single-cycle process. The maximal LNG capacity which can be reached for this process is around five MTPA because of construction limitations and exchangers' transportation limitations [8]. Nevertheless, the main reasons for extensive use of C3MR are related to utilizing of $\mathrm{MR}$ and recognition of its operational problems. As can be seen in Figure 3, propane is compressed in three stages and then divided into two parts. The first part $(23 \%$, stream C3-2) and the second are used to precool the compressed lean gas (NG-3) and MR (MR-4) to $-38.3{ }^{\circ} \mathrm{C}$. Along this path, the NG temperature is decreased in air and water cooler $\mathrm{AC}-1$ and $\mathrm{WC}-1$ and heat exchangers E-4, E-5, and E-6, respectively. While MR (6\% nitrogen, 
Table 2. Operating and design conditions of the existing NGL plant and added LNG part.

\begin{tabular}{lccccccc}
\hline Stream & $T\left({ }^{\circ} \mathrm{C}\right)$ & $P($ bar $)$ & Flow $\left(\mathrm{kmol} \mathrm{hr}^{-1}\right)$ & Stream & $T\left({ }^{\circ} \mathrm{C}\right)$ & $P($ bar $)$ & Flow $\left(\mathrm{kmol} \mathrm{hr}^{-1}\right)$ \\
\hline 31 & 22.0 & 64.4 & 25649 & 142 & 19.0 & 8.2 & 3403 \\
32 & 22.0 & 64.4 & 25612 & 144 & 2.4 & 5.1 & 865 \\
35 & 23.0 & 63.7 & 25607 & 145 & -1.6 & 4.5 & 423 \\
36 & 22.7 & 63.1 & 23814 & 146 & -0.1 & 4.5 & 423 \\
38 & 300.0 & 61.0 & 1792 & 147 & 1.6 & 4.5 & 1288 \\
39 & 60.0 & 59.4 & 1880 & 148 & 19 & 8.0 & 2712 \\
41 & 60.0 & 59.3 & 1800 & 149 & 77.3 & 22.6 & 4000 \\
42 & 71.5 & 65.2 & 1800 & 247 & -84.5 & 60.8 & 6697 \\
51 & 27.7 & 62 & 23814 & 248 & -87.2 & 30.0 & 22085 \\
52 & -35 & 61 & 23814 & 249 & 9.3 & 30.1 & 2714 \\
53 & -35 & 61 & 803 & 250 & -38.9 & 30.1 & 3143 \\
54 & -66.8 & 30.4 & 16315 & 256 & 14.3 & 29.8 & 2714 \\
55 & -48.8 & 30.4 & 803 & 261 & -15.4 & 29.8 & 3143 \\
56 & 16.2 & 28.8 & 22085 & NG-3 & -38.3 & 75.0 & 22085 \\
57 & 33.4 & 28.3 & 22085 & MR-1 & 35.0 & 48.0 & 29765 \\
58 & 36.3 & 30.2 & 1729 & MR-4 & -38.3 & 48.0 & 29765 \\
59 & 36.6 & 33.2 & 1729 & MR-5V & -130.0 & 48.0 & 8874 \\
63 & 8.7 & 30 & 954 & MR-5L & -130.0 & 48.0 & 20891 \\
64 & 104.6 & 30.8 & 776 & MR-7V & -166.4 & 2.9 & 8874 \\
81 & 89.3 & 22.8 & 1551 & MR-8V & -136.3 & 2.9 & 8874 \\
85 & 134.2 & 22.6 & 631 & MR-10 & -135.1 & 2.9 & 29765 \\
86 & 89.5 & 8.7 & 631 & MR-14 & 102.9 & 48.0 & 29765 \\
89 & 60.7 & 7.5 & 413 & C3-1 & 35.0 & 12.2 & 30746 \\
90 & 127.5 & 8.5 & 218 & C3-2 & 35.0 & 12.2 & 6964 \\
91 & 61.8 & 21.6 & 920 & C3-8 & -14.9 & 2.45 & 17186 \\
141 & 60.0 & 21.6 & 4000 & C3-10 & 14.1 & 5.47 & 30746 \\
\hline
\end{tabular}

Table 3. Specification of the existing columns.

\begin{tabular}{lcccc}
\hline Parameter & Demethanizer & Deethanizer & Depropanizer & Debutanizer \\
\hline Height $(\mathrm{m})$ & 38.35 & 36.9 & 32.9 & 31.1 \\
Diameter of 1st/2nd section $(\mathrm{m})$ & $4.2 / 2.0$ & $2.0 / 3.4$ & 4.2 & 2.3 \\
No. of theoretical stages & 18 & 32 & 29 & 27 \\
Type of tray & Ballast valve & Ballast valve & Ballast valve & Ballast valve \\
Condenser press (bar) & - & 30 & 21.6 & 7.5 \\
TOP/BTM operating press (bar) & $30 / 30.2$ & $30.5 / 30.8$ & $22.3 / 22.6$ & $8.2 / 8.5$ \\
Feed stages & $1,5,6,9,14$ & 12 & 13 & 15 \\
Side stream stages & 8,13 & - & - & - \\
\hline
\end{tabular}

$46 \%$ methane, $33 \%$ ethane, and $15 \%$ propane) is compressed in two stages and precooled in AC-2\&3, WC-2\&3, $\mathrm{E}-1, \mathrm{E}-2$, and $\mathrm{E}-3$. In the liquefaction section, NG is liquefied and subcooled in MPHX-1 and MPHX-2 by MR. Then with passing through V-ATM reaches to approximately $-166.5^{\circ} \mathrm{C}$ at atmospheric pressure. The design conditions of the added LNG production part are shown in Table 2. The MTA of added heat exchangers (WC, AC, E, and
MPHX) are considered $10,5,2$, and $1{ }^{\circ} \mathrm{C}$, respectively. It should be noted, the local ambient air temperature is assumed $37^{\circ} \mathrm{C}$ and the temperature of sea water is assumed $25{ }^{\circ} \mathrm{C}$.

The reason for the lower temperature of LNG in this article compared to other studies is related to the existence of $3.5 \%$ nitrogen in the feed gas. Accordingly, if the temperature of NG-5 (before reaching atmospheric pressure) 


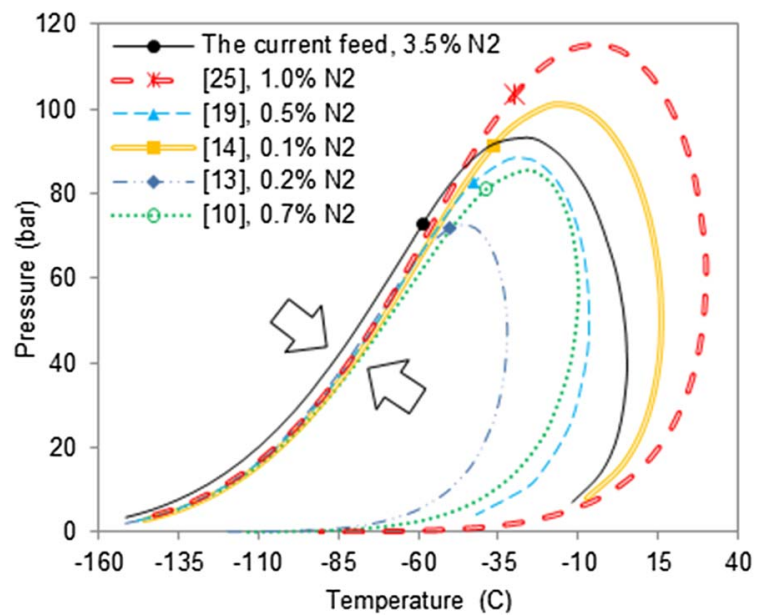

Fig. 4. Phase envelopes of the different feed gases.

is higher than $-162^{\circ} \mathrm{C}$, a large volume of natural gas exits from the top of D-6. Figure 4 compares the phase envelopes of the feed gases used in this study and some of the other researches. It is obvious that reaching to the subcooled zone with the current feed, needs more refrigeration.

\section{Simulation and validation}

In the literature, many process simulators with different thermodynamic packages, especially PR and similar equations, were used to simulate natural gas cryogenic processes $([2,3,8]$ and $[27])$. In this way, simulation of the entire existing NGL plant, Figure 2, was carried out in Aspen Plus $^{\circledR}$ (V.10) with three different thermodynamic packages (PR, modified PR, and SRK). Modified PR is the PR which its binary interaction coefficients $\left(K_{i j}\right)$ are corrected in accordance with Table A1. The validation of the simulation results is done by comparing with industrial plant data. The details of validation of the thermodynamic packages are presented in Table A2. It indicates that the differences of these packages are significant especially in prediction of high concentrations of heavy components. According to this table, modified PR has the least error $(3.13 \%)$ in the validation of the existing NGL plant than other thermodynamic packages.

\section{Optimization}

\subsection{Objective function}

Earned profit is the important parameter needs to be considered in the modification of chemical units. The profit of the existing NGL plant is due to the sale of its products minus the operating costs. In addition to the increased revenue, increased capital and operating costs should be determined in adding the LNG production part. It is worth noting that the equipments which exceed their acceptable operating capacity in optimization procedure are modified with adding appropriate equipments. Otherwise, the
Table 4. Basic cost of products and utilities (2016).

\begin{tabular}{lcc}
\hline Component & \multicolumn{1}{c}{ Cost } & Ref. \\
\hline NG & $2.50 \$ \mathrm{MMBtu}^{-1}$ & {$[33]$} \\
LNG & $6.06 \$ \mathrm{MMBtu}^{-1}$ & {$[34]$} \\
Ethane & $0.325 \$ \mathrm{~kg}^{-1}$ & {$[35]$} \\
Propane & $0.325 \$ \mathrm{~kg}^{-1}$ & {$[35]$} \\
Electricity & $0.078 \$ \mathrm{kWh}^{-1}$ & APEA $^{\circledR}(\mathrm{V} .10)$ \\
LP steam, 100 psi & $8.14 \$ \mathrm{klb}^{-1}$ & APEA $^{\circledR}(\mathrm{V} .10)$ \\
\hline
\end{tabular}

existing equipment is replaced with the new one. The objective function is defined as follows:

$$
\text { Maximize }: \mathrm{EP}=\mathrm{IAR}-\mathrm{TIAC},
$$

where

$$
\begin{gathered}
\mathrm{IAR}=\mathrm{AR}_{\text {Integrated plant }}-\mathrm{AR}_{\mathrm{NGL} \text { plant }}, \\
\mathrm{TIAC}=0.33 \mathrm{TICI}+\mathrm{TIOC}, \\
\mathrm{TICI}=1.18\left(\mathrm{TIBM}+\mathrm{C}_{\text {site }}+\mathrm{C}_{\text {buildings }}\right)+\mathrm{C}_{\mathrm{WC}}, \\
\mathrm{TIBM}=\sum_{\text {i:each of added process equipment }} \mathrm{BM}_{\mathrm{i}}, \\
\mathrm{C}_{\text {site }}=5 \% \text { TIBM }, \\
\mathrm{C}_{\text {buildings }}=5 \% \text { TIBMipment } \\
\mathrm{C}_{\mathrm{WC}}=5 \% \text { TICI }, \\
\text { TIOC }=\text { ISC }+ \text { IEC. },
\end{gathered}
$$

As can be seen, concerning to Table 4, the value of increased annualized revenue is determined. Next, the total increased annualized cost is calculated with the assumption of 3-year payback period. Various methods exist to estimate investment costs, which have different accuracy due to their complexity. The Guthrie method, with precision of about $20 \%$, is applied to determine the total increased capital investment in this study [36]. The bare-module cost consists of installed and purchased equipment cost which is estimated by Aspen Process Economic Analyzer ${ }^{\circledR}$ (V.10). Installed and purchased equipment cost represents the total direct material and labor, and the bare equipment costs associated with the project component, respectively. Five percent of TIBM is considered for the cost of site preparation and building costs, and the working capital can be estimated at $5 \%$ of the total capital investment. At last, total increased operating cost is determined by the summation of increased electricity and steam costs. It is necessary to mention that the integrated plant is anticipated to operate 300 days a year. 


\subsection{Design variables and constraints}

One of the important issues in the optimization problems is the selection of independent variables that have significant effects on the performance of the objective function. To this aim, at first, all of independent variables of the integrated plant were determined. Then with the help of sensitivity analysis, the effects of changing these variables on the objective function were evaluated. Variables with high impact on the objective function were chosen as design variables. MR composition (included nitrogen, methane, ethane, and propane), high and low pressure of MR (outlet pressure of K-4, and V-7\&8), inlet gas pressure of the LNG production part (outlet pressure of 106-K101), and operating pressure of demethanizer column are variables of the optimization problem. Upper and lower limits of these variables, concerning process recognition and maintenance of existing equipments as much as possible, are shown in equations (11)-(18). It should be noted during the optimization, hydraulic conditions of each column, especially the demethanizer, had been checked that do not have any operational problems.

$$
\begin{aligned}
& 6 \leq x_{1}: \mathrm{N}_{2} \text { content in MR, mole } \% \leq 10 \\
& 42 \leq x_{2}: \mathrm{C}_{1} \text { content in MR, } \operatorname{mole} \% \leq 47, \\
& 30 \leq x_{3}: \mathrm{C}_{2} \text { content in MR, mole } \% \leq 39, \\
& 13 \leq x_{4}: \mathrm{C}_{3} \text { content in MR, mole } \% \leq 20 \text {, } \\
& 45 \leq x_{5}: P_{\text {Out }, \mathrm{K}-4}, \quad \text { bar } \leq 51 \\
& 2.5 \leq x_{6}: \mathrm{P}_{\text {Out, } \mathrm{V}-7 \& 8}, \quad \text { bar } \leq 3.2 \\
& 55 \leq x_{7}: P_{\text {Inlet gas of the LNG production part }}, \quad \text { bar } \leq 75, \\
& 25 \leq x_{8}: P_{105-\mathrm{C} 101}, \quad \text { bar } \leq 30
\end{aligned}
$$

\subsection{Optimization method}

According to the literature, most researches done in the field of NG liquefaction optimization were used one of the deterministic, stochastic, or KBO methods. Each of these offers several benefits in terms of calculation time, convergence and ease of implementation. Whereas, a statistical method was used in this research to full recognition of the process and simplify the optimization problem concerning
Table 5. Tuning parameter of GA.

\begin{tabular}{lc}
\hline Tuning parameters & Value \\
\hline Population size & 300 \\
Crossover fraction & 0.8 \\
Mutation & Adaptive feasible \\
Selection method & Stochastic uniform \\
Crossover function & Scatter \\
Number of generations & 800 \\
\hline
\end{tabular}

the extent and complexity of the integrated plant. In this way, D-optimal design approach was utilized for developing a surrogate model which predicted the plant behavior with high accuracy. A D-optimal is a computer-generated design, which chooses runs that minimizes the determinant of the variance-covariance matrix of the parameter estimates of the model. This has the effect of minimizing the volume of the joint confidence ellipsoid for the coefficients. The optimal approach has more flexibility and lower runs in compared with the standard designs such as central composite or Box-Behnken. In addition it supports irregular experimental regions, and mixture and process variables in the same design. Accordingly, the effects of design variables of the integrated plant on the objective function were investigated through conducting 155 simulation runs based on the design matrix of D-optimal approach in DesignExpert $^{\circledR}$ (V.10). The correctness of the generated surrogate model was verified by several statistical criterions. Then, concerning the nonlinearity of the model behavior, a hybrid method consists of the GA and SQP was used to find the global optimal point of the surrogate model $[17,37]$. The GA and SQP as powerful stochastic and deterministic optimization methods are used widely for solving optimization problems. The GA searches the global solution in a population which is randomly generated. This method is able to solve nonlinear problems after a large number of generations. The SQP, as a fast method, is very sensitive to the choice of initial point and not able to solve the highly nonlinear problems. While the hybrid GA-SQP method is able to determine the final solution considerably faster than the GA while it is not sensitive to the initial point. In this method, the result of GA as an initial guess was used in SQP to improve the results. The tuning parameters of this method used in MATLAB $^{\circledR}$ are listed in Table 5.

\section{Results and discussion}

\subsection{Model regression and statistical analysis}

The obtained results from the simulation runs were analyzed to determine the quadratic-quadratic model, mixture and process orders, for the earned profit from the modification of the existing NGL plant. The regressed model is presented in equation (19) and its coefficients based on the coded and actual values are shown in Table A3. 


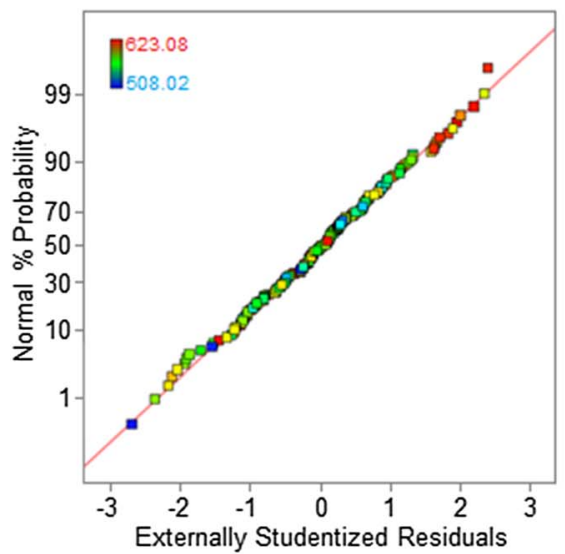

(a)

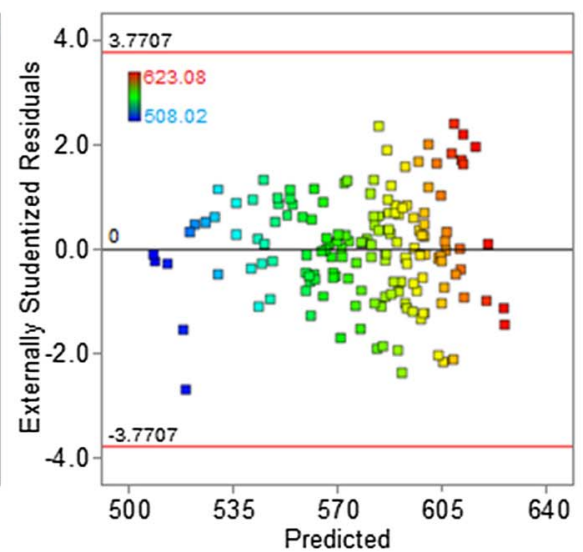

(b)

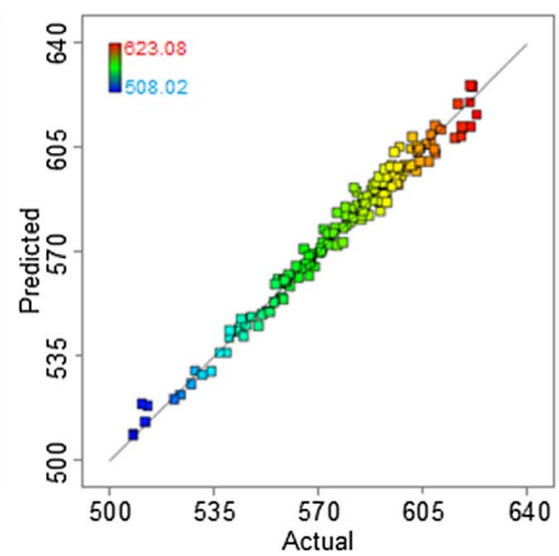

(c)

Fig. 5. (a) Normal plot of residuals, (b) residuals vs. predicted, (c) predicted vs. actual data.

Table 6. Optimal conditions and corresponding observed and predicted objective function.

\begin{tabular}{|c|c|c|c|c|c|c|c|c|c|c|}
\hline \multicolumn{4}{|c|}{ Mixture variable } & \multicolumn{4}{|c|}{ Process variable } & \multicolumn{3}{|c|}{ Objective function } \\
\hline$x_{1}$ & $x_{2}$ & ${ }_{\mathrm{ol})}^{x_{3}}$ & $x_{4}$ & $x_{5}$ & $x_{6}$ & )$^{x_{7}}$ & $x_{8}$ & Predicted & $\begin{array}{l}\text { Observed* } \\
-1 \text { ) }\end{array}$ & $\begin{array}{c}\text { Error } \\
(\%)\end{array}$ \\
\hline 9.01 & 43.23 & 31.55 & 16.22 & 50.72 & 3.19 & 66.60 & 25.99 & 623.62 & 628.32 & 0.75 \\
\hline
\end{tabular}

* Observed means the value is predicted by simulated plant.

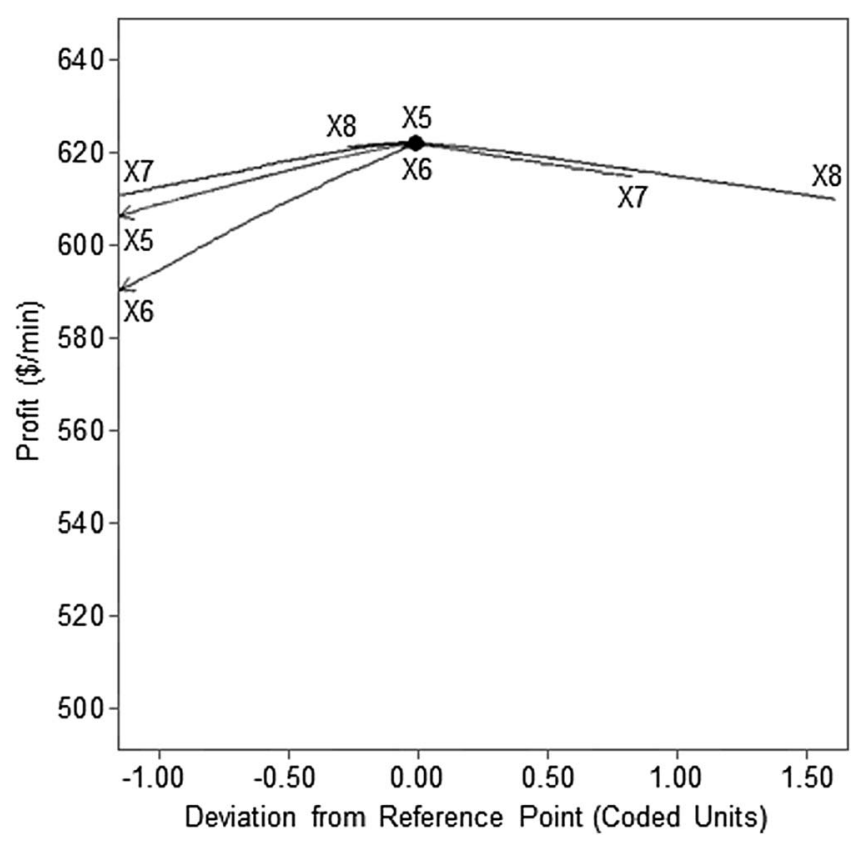

Fig. 6. Perturbation plot at the optimal conditions.

$$
\text { Objective function }=\sum_{i=1}^{88} a_{i} f_{i}(X)
$$

where $X=\left[x_{1}, x_{2}, x_{3}, x_{4}, x_{5}, x_{6}, x_{7}, x_{8}\right]$.
The coded equation can be used to make predictions about the response for given levels of each factor. The high and low levels of the factors are coded as +1 and -1 , respectively. This type of equation is useful for identifying the relative impact of the factors by comparing their coefficients. While for predicting of response in the equation included actual factors, the levels should be specified in the original units. This equation cannot be used to determine the relative impact of each factor because the coefficients are scaled to accommodate the units of each factor and the intercept is not at the center of the design space.

Several statistical criterions should be checked to verify the correctness of the generated model. Fisher test via dividing the model mean square by its residual mean square is a statistical significance test used in the ANOVA table. The results of ANOVA for the earned profit show that the model is significant for the $95 \%$ confidence interval with $F$-value of 49.60 . The insignificant terms with $p$-value greater than 0.1 , were removed from the model to improve its regression quality and the optimization results. However, as can be seen in the ANOVA, some of the insignificant terms in reason to the hierarchy of model were preserved. It should be noted that due to the lack of repetition in the simulation runs, lack-of-fit test is not practical. Adequate precision is a signal-to-noise ratio that investigates the precision of the developed model. It compares the range of the predicted values at the design points to the average prediction error. Ratios greater than 4 are favorable for adequate precision. The value of this parameter for the proposed 


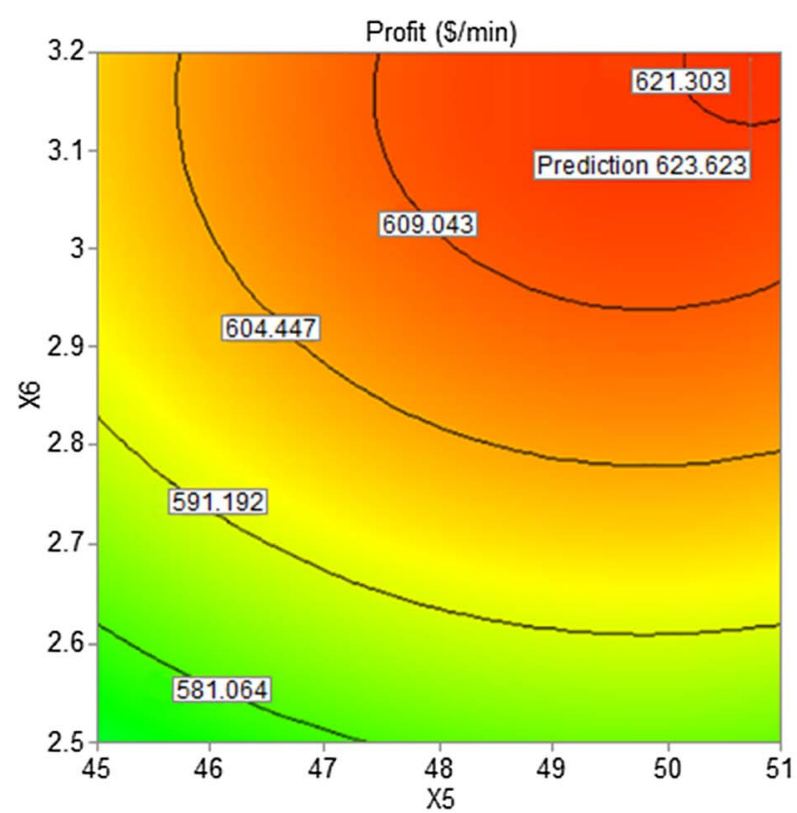

(a)

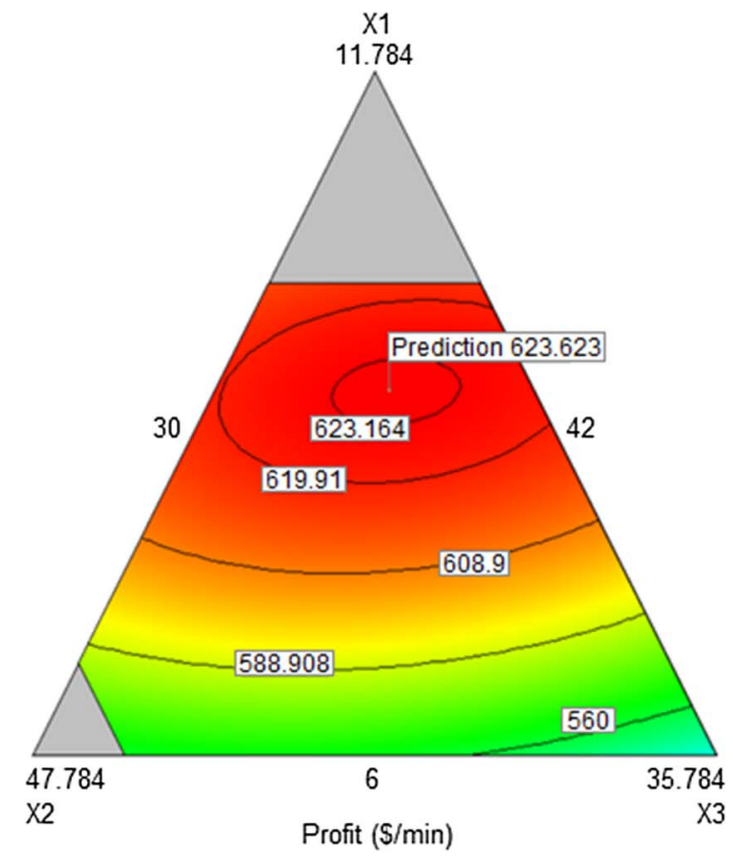

(c)

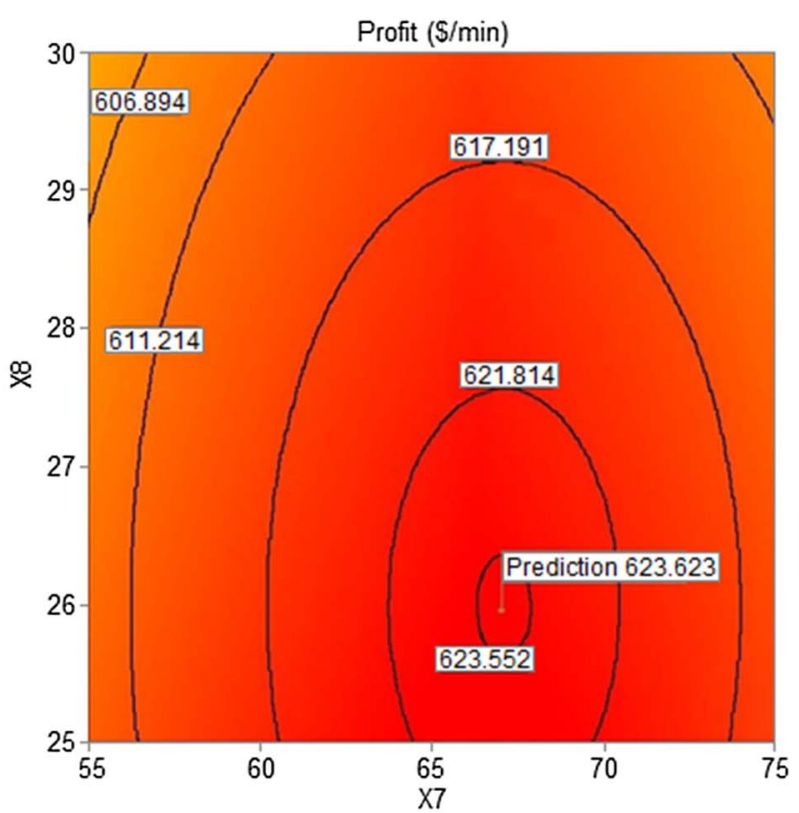

(b)

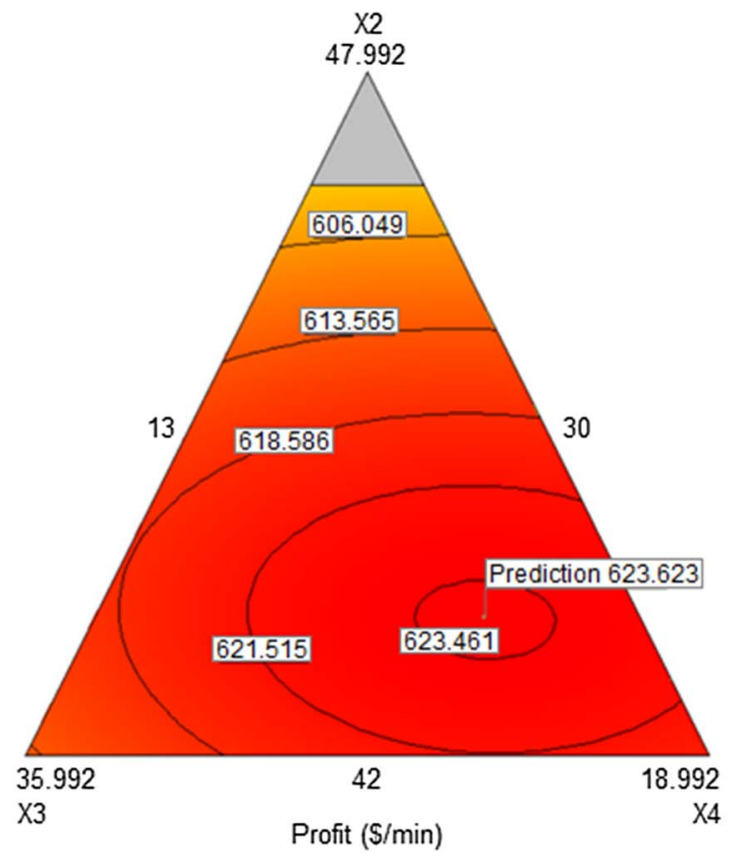

(d)

Fig. 7. Effects of $(\mathrm{a}, \mathrm{b})$ process and $(\mathrm{c}, \mathrm{d})$ mixture variables on the objective function at the optimal conditions.

model is equal to 32.214 . Another criterion, $R$-squared, is a measure of the amount of variation around the mean explained by the model. It can be artificially inflated by simply continuing to add terms to the model, even if the terms are not statistically significant. The adjusted $R$-squared plateaus when insignificant terms are added to the model and the predicted $R$-squared will decrease when there are too many insignificant terms. Adjusted $R$-squared is a measure of the amount of variation around the mean explained by the model, adjusted for the number of terms in the model, while the predicted $R$-squared indicates how well a developed model predicts responses for new observations. High values of the mentioned parameters (0.9807 for $R$-squared, 0.9610 for adjusted $R$-squared, and 0.9215 for predicted $R$-squared) indicate that the second-order fitted model is significant for describing the integrated NGL/ LNG plant.

Examining the residuals by diagnostic plots are the other criterions that are checked to confirm the fitted model. To this aim, at first, the normal probability of the studentized residuals was plotted. As shown in Figure 5a, convergence of the residuals on the red line indicates the 


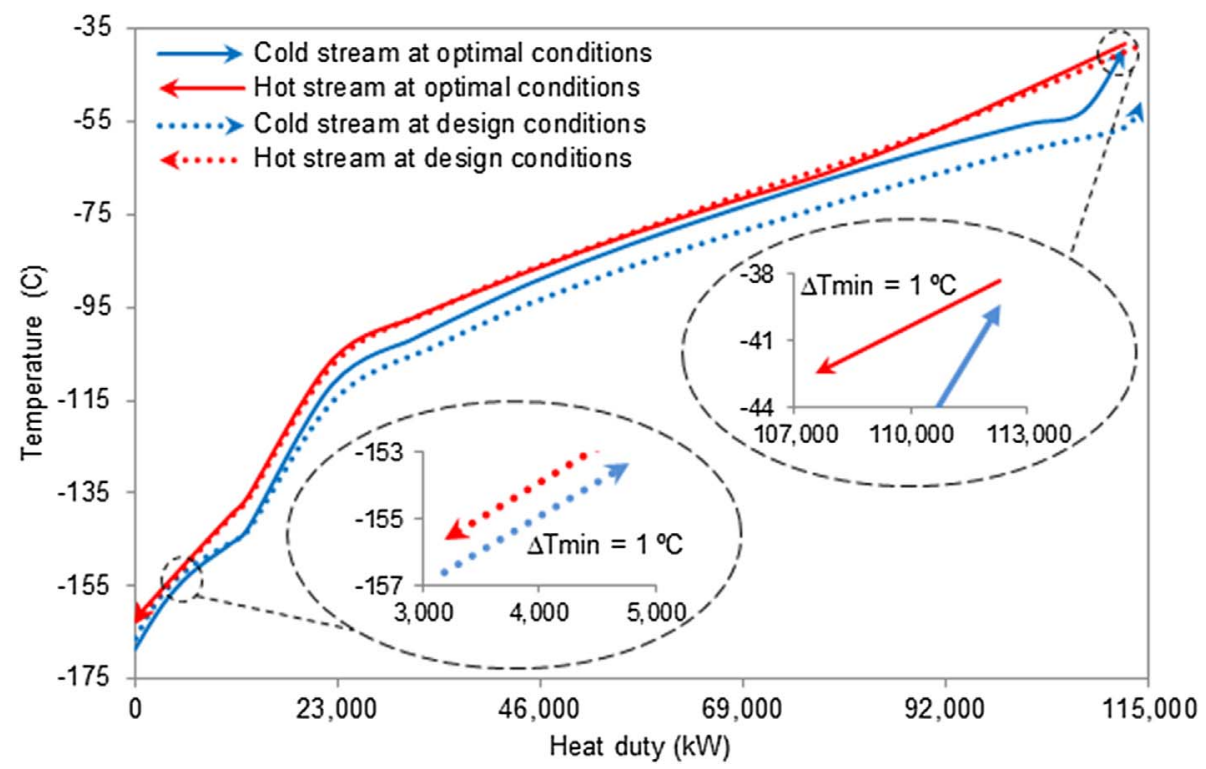

Fig. 8. Composite curves of the liquefaction section at the design and optimal conditions.

Table 7. Liquefaction efficiency comparison.

\begin{tabular}{lccrr}
\hline Author & Year & Refrigeration system & SPC $\left(\mathrm{kWh} \mathrm{kg}^{-1} \mathrm{LNG}\right)$ & Ref. \\
\hline Wang et al. ${ }^{*}$ & 2013 & C3MR & 0.408 & {$[38]$} \\
Mehrpooya et al. & 2014 & C3MR & 0.391 & {$[27]$} \\
Wang et al. ${ }^{*}$ & 2014 & C3MR & 0.358 & {$[38]$} \\
Khan et al. & 2014 & KSMR & 0.386 & {$[26]$} \\
Ghorbani et al. & 2016 & C3MR & 0.359 & {$[29]$} \\
Ansarinasab and Mehrpooya & 2017 & C3MR-ARS & 0.207 & {$[39]$} \\
Current study & 2020 & C3MR & 0.347 & - \\
\hline
\end{tabular}

* This note is extracted from the review paper of Song et al. [38]

satisfaction of the normality assumption. Another step was plotting the externally studentized residuals versus predicted values. In an adequate model, the data without a particular trend scatter randomly above and below the zero residual line. According to this and with attention to Figure 5b, the variances of the error are constant and there are no outliers. The final test is concerned with the plot of predicted versus actual data which indicates the amount of deviation of actual data from the model predicted data. Figure 5c shows that the fitted model, predicts the earned profit data with enough precision.

\subsection{Optimization results}

As mentioned earlier, the optimization of the generated surrogate model was applied to detecting the maximum profit earned from the modification of the existing NGL plant by adding the LNG production part. The obtained optimum mixture and process variables and their corresponding predicted response of the model are tabulated in Table 6 . The comparison of predicted response with its observed value represents the high accuracy of the modeling.
The details of determination of the objective function including the changes of type and quantity of products and changes in operating and investment costs are presented in Table A4-Table A6. It should be noted that determination of the bare-module cost of multi-stream heat exchangers needs to design specifications of them. For the sack of reliability and validity, Aspen $\operatorname{EDR}^{\circledR}$ (V.10) was used in obtaining appropriate, accurate, and acceptable sizing and specifications of MPHX-1\&2. The overall geometry of these heat exchangers is shown in Table A7.

In order to evaluate the behavior of the process factors at the optimal point, the perturbation plot was studied. In this plot, the response is drawn by varying only one factor over its range while the other factors are held constant. Figure 6 illustrates the effect of high and low pressure of MR, inlet gas pressure of the LNG production part, and operating pressure of the demethanizer column at the optimal conditions which shown in Table 6. According to Figure 6 , the earned profit increased with increasing high and low pressure of MR ( $x_{5}$ and $\left.x_{6}\right)$; although the steep curvature in the behavior of low pressure of MR $\left(x_{6}\right)$ implied that the profit was more rapid in response to this factor. 
The contour plot shown in Figure $7 \mathrm{a}$, confirms the above results. While there are trades-off in the detection of the optimal values of inlet gas pressure of the LNG production part $\left(x_{7}\right)$ and operating pressure of the demethanizer column $\left(x_{8}\right)$. As can be seen in Figure 6 , increasing the inlet gas pressure of the LNG production part $\left(x_{7}\right)$ at first increases the earned profit by decreasing the required heat transfer area in heat exchangers. However, keep increasing the inlet gas pressure warms the gas and increases the bare-module cost and electricity consumed of 106-K101 and subsequently decreases the profit. Moreover, reducing the operating pressure of the demethanizer column $\left(x_{8}\right)$ increases the ethane recovery. On the other hand, reducing the operating pressure decreases the amount of produced LNG, increases the bare-module cost and electricity consumed of 106-K101, and as indicated in Table A4 increases the steam consumed. Accordingly, an optimal value was found for the dimethanizer columns' pressure, and contrary to expectation this variable does not fell on the lower bound. The contour plot shown in Figure 7b, confirms the observed behavior of $x_{7}$ and $x_{8}$ variables. Investigating the effects of mixture variables on the economic objective function at the optimal conditions requires the study of ternary plots. Such plots were obtained considering three mixture factors at a time while keeping the others constant. Figure $7 \mathrm{c}$ represents the simultaneous effects of nitrogen, methane, and ethane concentration on the model response at the optimal point. It was found that keeping nitrogen constant at any values and increasing methane (decreasing ethane) or vice versa did not contribute to a significant change in the earned profit around the optimal point. Whereas, increasing nitrogen causes rapid increase in the earned profit especially at the middle levels of methane and ethane.

The interaction effects of nitrogen, methane, and propane when the other factors are at the optimal conditions are similar to Figure $7 \mathrm{c}$. Figure $7 \mathrm{~d}$ indicates the ternary plot of methane, ethane, and propane when the other factors are at optimal values. It shows that variations of methane around the optimal conditions are more effective than ethane and propane changes.

Actually, according to the above-mentioned due to the curvature of response, the optimum values of the mixture variables located neither at its upper nor its lower levels, but somewhere within the range. Also it should be noted that as can be seen in Table A3, the greatest coefficients are related to the mixture variables. Therefore all of these factors have a strong impact on the economic objective function while Figures $7 \mathrm{c}$ and $7 \mathrm{~d}$ just evaluate the effects of mixture variables when the other factors are at optimal conditions. The determination of optimal values of design variables, especially MR composition, in addition to increasing the earned profit, improve thermodynamic efficiency by closing hot and cold composite curves in the liquefaction section of the LNG production part, as shown in Figure 8.

According to the literature review, most articles in the field of NGL/LNG integration were used liquefaction efficiency, SPC, as the objective function. However, although the presented paper is maximized the earned profit, with respect to determination of the optimal conditions especially MR composition, the amount of electrical power consumed, Table A5, for production of the LNG is decreased. It should be noted the greatest reduction is related to electrical power consumption of the compressors of the MR cycle. As seen in Table 7, there is low range in the SPC values of C3MR process and the optimized proposed integrated plant has high liquefaction efficiency among similar conventional cases. Moreover the structure and operating conditions of the LNG production part, the composition of the feed gas is effective on the SPC.

\section{Conclusion}

The evaluation of integrating an existing operational NGL plant with adding an appropriate LNG production part was performed. In this way, with respects to the conditions of no structural changes in the current units and keeping the existing equipments as much as possible, the structure of the LNG production part was determined. Whereas the analysis of the phase envelope curves of different compositions of feed gases showed that the amount of $\mathrm{N}_{2}$ in feed has a reverse effect on the LNG temperature. In the next, D-optimal design approach was utilized to full recognition of the integrated process and generation of a surrogate model for determination of the earned profit. MR composition (nitrogen, methane, ethane, and propane), high and low pressure of MR, inlet gas pressure of the LNG production part, and operating pressure of demethanizer column were introduced as manipulated variables. Accordingly, a quadratic-quadratic model was developed and statistical tests confirmed its high accuracy (0.98 for $R$-squared, 0.96 for adjusted $R$-squared, and 0.92 for predicted $R$-squared). The coefficients of the coded surrogate model indicated that the composition of MR has the most effect in the earned profit. At the last step, the optimization of the integrated plant was on the agenda. In this way, the optimal operating conditions from the surrogate model were obtained using a hybrid optimization method that consists of the GA and SQP. Then, the effects of the main process variables and MR composition on the earned profit were investigated with perturbation and contour plots. Accordingly, the optimum values of the mixture variables located neither at its upper nor its lower levels, but somewhere within the range. The increasing high and low pressure of MR caused an increase in the objective function with different gradients. While increasing the inlet gas pressure of the LNG production part at first increased the profit but with keeping this trend, the profit was decreased. Moreover, an optimal value was found for demethanizer pressure and it did not fall on the lower bound. Finally, the optimization results indicated that with shifting from the NGL plant to the integrated NGL/LNG, a profit equal to $623.62 \$ \mathrm{~min}^{-1}$ can be earned. In addition to the increased earned profit in the developed integrated plant, the thermodynamic efficiency was improved by closer matching of hot and cold composite curves in the liquefaction section. Furthermore, the optimized proposed integrated plant has acceptable SPC with the value of $0.347 \mathrm{kWh} \mathrm{kg}^{-1}$ LNG. 


\section{References}

1 International Energy Agency, Market Report Series: Gas 2019, https://www.iea.org/topics/naturalgas/ (accessed 16 November 2019).

2 Castillo L., Dahouk M.M., Di Scipio S., Dorao C.A. (2013) Conceptual analysis of the precooling stage for LNG processes, Energy Convers. Manage. 66, 41-47.

3 Lim W., Lee I., Tak K., Cho J.H., Ko D., Moon I. (2014) Efficient configuration of a natural gas liquefaction process for energy recovery, Ind. Eng. Chem. Res. 53, 5, 1973-1985.

4 Ghorbani B., Hamedi M.H., Amidpour M., Mehrpooya M. (2016) Cascade refrigeration systems in integrated cryogenic natural gas process (natural gas liquids (NGL), liquefied natural gas (LNG) and nitrogen rejection unit (NRU)), Energy 115, 88-106.

5 Khan M.S., Karimi I.A., Wood D.A. (2017) Retrospective and future perspective of natural gas liquefaction and optimization technologies contributing to efficient LNG supply: A review, J. Nat. Gas Sci. Eng. 45, 165-188.

6 Mazyan W., Ahmadi A., Ahmed H., Hoorfar M. (2016) Market and technology assessment of natural gas processing: A review, J. Nat. Gas Sci. Eng. 30, 487-514.

7 Khan M.S., Lee S., Lee M. (2012) Optimization of single mixed refrigerant natural gas liquefaction plant with nonlinear programming, Asia-Pacific J. Chem. Eng. 7, S62-S70.

8 Lee S., Long N.V.D., Lee M. (2012) Design and optimization of natural gas liquefaction and recovery processes for offshore floating liquefied natural gas plants, Ind. Eng. Chem. Res. 51, 30, 10021-10030.

9 Lim W., Choi K., Moon I. (2013) Current status and perspectives of liquefied natural gas (LNG) plant design, Ind. Eng. Chem. Res. 52, 9, 3065-3088.

10 Shirazi M.M.H., Mowla D. (2010) Energy optimization for liquefaction process of natural gas in peak shaving plant, Energy 35, 7, 2878-2885.

11 Khan M.S., Lee M. (2013) Design optimization of single mixed refrigerant natural gas liquefaction process using the particle swarm paradigm with nonlinear constraints, Energy 49, 146-155.

12 Moein P., Sarmad M., Ebrahimi H., Zare M., Pakseresht S., Vakili S.Z. (2015) APCI-LNG single mixed refrigerant process for natural gas liquefaction cycle: analysis and optimization, J. Nat. Gas Sci. Eng. 26, 470-479.

13 Lee I., Moon I. (2016) Total cost optimization of a single mixed refrigerant process based on equipment cost and life expectancy, Ind. Eng. Chem. Res. 55, 39, 10336-10343.

14 Alabdulkarem A., Mortazavi A., Hwang Y., Radermacher R., Rogers P. (2011) Optimization of propane pre-cooled mixed refrigerant LNG plant, Appl. Therm. Eng. 31, 6-7, 1091-1098.

15 Wang M., Zhang J., Xu Q., Li K. (2011) Thermodynamicanalysis-based energy consumption minimization for natural gas liquefaction, Ind. Eng. Chem. Res. 50, 22, 12630-12640.

16 Wang M., Zhang J., Xu Q. (2012) Optimal design and operation of a C3MR refrigeration system for natural gas liquefaction, Comput. Chem. Eng. 39, 84-95.

17 Hwang J.H., Roh M.I., Lee K.Y. (2013) Determination of the optimal operating conditions of the dual mixed refrigerant cycle for the LNG FPSO topside liquefaction process, Comput. Chem. Eng. 49, 25-36.

18 Sanavandi H., Ziabasharhagh M. (2016) Design and comprehensive optimization of C3MR liquefaction natural gas cycle by considering operational constraints, J. Nat. Gas Sci. Eng. 29, 176-187.

19 Khan M.S., Karimi I.A., Lee M. (2016) Evolution and optimization of the dual mixed refrigerant process of natural gas liquefaction, Appl. Therm. Eng. 96, 320-329.

20 Sun H., Ding D.H., He M., Sun S.S. (2016) Simulation and optimization of AP-X process in a large-scale LNG plant, J. Nat. Gas Sci. Eng. 32, 380-389.

21 Ding H., Sun H., Sun S., Chen C. (2017) Analysis and optimization of a mixed fluid cascade (MFC) process, Cryogenics 83, 35-49.

22 Nawaz A., Qyyum M.A., Qadeer K., Khan M.S., Ahmad A., Lee S., Lee M. (2019) Optimization of mixed fluid cascade LNG process using a multivariate Coggins step-up approach: Overall compression power reduction and exergy loss analysis, Int. J. Ref. 104, 189-200.

23 He T., Liu Z., Ju Y., Parvez A.M. (2019) A comprehensive optimization and comparison of modified single mixed refrigerant and parallel nitrogen expansion liquefaction process for small-scale mobile LNG plant, Energy 167, 1-12.

24 Vatani A., Mehrpooya M., Tirandazi B. (2013) A novel process configuration for co-production of NGL and LNG with low energy requirement, Chem. Eng. Proc. Proc. Intens. 63, 16-24.

25 He T., Ju Y. (2014) Design and optimization of a novel mixed refrigerant cycle integrated with NGL recovery process for small-scale LNG plant, Ind. Eng. Chem. Res. 53, 13, 5545-5553.

26 Khan M.S., Chaniago Y.D., Getu M., Lee M. (2014) Energy saving opportunities in integrated NGL/LNG schemes exploiting: Thermal-coupling common-utilities and process knowledge, Chem. Eng. Proc. Proc. Intens. 82, 54-64.

27 Mehrpooya M., Hossieni M., Vatani A. (2014) Novel LNGbased integrated process configuration alternatives for coproduction of LNG and NGL, Ind. Eng. Chem. Res. 53, $45,17705-17721$.

28 Uwitonze H., Lee I., Hwang K.S. (2016) Alternatives of integrated processes for coproduction of LNG and NGLs recovery, Chem. Eng. Proc. Proc. Intens. 107, 157-167.

29 Ghorbani B., Hamedi M.H., Amidpour M. (2016) Development and optimization of an integrated process configuration for natural gas liquefaction (LNG) and natural gas liquids (NGL) recovery with a nitrogen rejection unit (NRU), $J$. Nat. Gas Sci. Eng. 34, 590-603.

30 Ghorbani B., Shirmohammadi R., Mehrpooya M. (2018) A novel energy efficient LNG/NGL recovery process using absorption and mixed refrigerant refrigeration cycles-Economic and exergy analyses, Appl. Therm. Eng. 132, 283-295.

31 Ghorbani B., Hamedi M.H., Amidpour M., Shirmohammadi R. (2017) Implementing absorption refrigeration cycle in lieu of DMR and C3MR cycles in the integrated NGL, LNG and NRU unit, Int. J. Ref. 77, 20-38.

32 Ghorbani B., Mehrpooya M., Shirmohammadi R., Hamedi M.H. (2018) A comprehensive approach toward utilizing mixed refrigerant and absorption refrigeration systems in an integrated cryogenic refrigeration process, J. Cleaner Prod. 179, 495-514.

33 EIA (2019) Henry Hub Natural Gas Spot Price, https:// www.eia.gov/dnav/ng/hist/rngwhhdm.htm (accessed 16 November.

34 METI, Spot LNG Price Statistics, https://www.meti.go.jp/ english/statistics/sho/slng/index.html (accessed 16 November 2019). 
35 Jiang H., Zhang S., Jing J., Zhu C. (2019) Thermodynamic and economic analysis of ethane recovery processes based on rich gas, Appl. Therm. Eng. 148, 105-119.

36 Seider W.D., Seader J.D., Lewin D.R. (2009) Product and process design principles: synthesis, analysis and evaluation, Wiley, USA, pp. 534-601.

37 Ku N.K., Lee J.C., Roh M.I., Hwang J.H., Lee K.Y. (2012) Multi-floor layout for the liquefaction process systems of LNG FPSO using the Optimization Technique, J. Soc. Naval Arch. Korea 49, 1, 68-78.
38 Song Q., Zhang J.P., Zhao Z., Luo J.L., Wang Q., Chen G.M. (2019) Development of natural gas liquefaction processes using mixed refrigerants: a review of featured process configurations and performance, J. Zhejiang Univ-Sci A $\mathbf{2 0 ,}$ $10,727-780$.

39 Ansarinasab H., Mehrpooya M. (2017) Advanced exergoeconomic analysis of a novel process for production of LNG by using a single effect absorption refrigeration cycle, Appl. Therm. Eng. 114, 719-732. 
Appendix

Table A1. Binary interaction coefficients $\left(K_{i j}\right)$ of the modified PR package.

\begin{tabular}{|c|c|c|c|c|c|c|c|c|c|c|c|c|c|c|c|c|}
\hline & $\mathrm{N}_{2}$ & $\mathrm{CO}_{2}$ & $\mathrm{H}_{2} \mathrm{~S}$ & $\mathrm{C}_{1}$ & $\mathrm{C}_{2}$ & $\mathrm{C}_{3}$ & $i-\mathrm{C}_{4}$ & $n-\mathrm{C}_{4}$ & $i-\mathrm{C}_{5}$ & $n-\mathrm{C}_{5}$ & $\mathrm{C}_{6}$ & $\mathrm{C}_{7}$ & $\mathrm{COS}$ & M-MER & E-MER & $\mathrm{H}_{2} \mathrm{O}$ \\
\hline $\mathrm{N}_{2}$ & & -0.0200 & 0.1676 & 0.036 & 0.05 & 0.08 & 0.095 & 0.09 & 0.095 & 0.1 & 0.149 & 0.1439 & 0 & 0 & 0 & -0.3156 \\
\hline $\mathrm{CO}_{2}$ & -0.0200 & & 0.1 & 0.1 & 0.1298 & 0.135 & 0.1298 & 0.1298 & 0.125 & 0.125 & 0.125 & 0.1199 & 0 & 0 & 0 & 0.0445 \\
\hline $\mathrm{H}_{2} \mathrm{~S}$ & 0.1676 & 0.1 & & 0.085 & 0.084 & 0.075 & 0.05 & 0.06 & 0.06 & 0.065 & 0.06 & 0.06 & 0 & 0 & 0 & 0.0819 \\
\hline $\mathrm{C}_{1}$ & 0.036 & 0.1 & 0.085 & & 0.0022 & 0.0068 & 0.0131 & 0.0123 & 0.0176 & 0.0179 & 0.0235 & 0.0289 & 0.0289 & 0.0592 & 0.0592 & 0.5 \\
\hline $\mathrm{C}_{2}$ & 0.05 & 0.1298 & 0.084 & 0.0022 & & 0.0013 & 0.0046 & 0.0041 & 0.0074 & 0.0076 & 0.0114 & 0.0153 & 0.025 & 0.0694 & 0.0608 & 0.5 \\
\hline $\mathrm{C}_{3}$ & 0.08 & 0.135 & 0.075 & 0.0068 & 0.0013 & & 0.001 & 0.0008 & 0.0026 & 0.0027 & 0.0051 & 0.0079 & 0.0105 & 0.0657 & 0.0564 & 0.5 \\
\hline$i-\mathrm{C}_{4}$ & 0.095 & 0.1298 & 0.05 & 0.0131 & 0.0046 & 0.001 & & 0 & 0.0003 & 0.0004 & 0.0016 & 0.0032 & 0 & 0.0399 & 0.0602 & 0.5 \\
\hline$n-\mathrm{C}_{4}$ & 0.09 & 0.1298 & 0.06 & 0.0123 & 0.0041 & 0.0008 & 0 & & 0.0005 & 0.0005 & 0.0019 & 0.0036 & 0.0158 & 0.072 & 0.0369 & 0.5 \\
\hline$i-\mathrm{C}_{5}$ & 0.095 & 0.125 & 0.06 & 0.0176 & 0.0074 & 0.0026 & 0.0003 & 0.0005 & & 0 & 0.0004 & 0.0015 & 0 & 0.0594 & 0.0594 & 0.5 \\
\hline$n-\mathrm{C}_{5}$ & 0.1 & 0.125 & 0.065 & 0.0179 & 0.0076 & 0.0027 & 0.0004 & 0.0005 & 0 & & 0.0004 & 0.0014 & 0 & 0.0593 & 0.0593 & 0.48 \\
\hline $\mathrm{C}_{6}$ & 0.149 & 0.125 & 0.06 & 0.0235 & 0.0114 & 0.0051 & 0.0016 & 0.0019 & 0.0004 & 0.0004 & & 0.0003 & 0 & 0.058 & 0.058 & 0.5 \\
\hline $\mathrm{C}_{7}$ & 0.1439 & 0.1199 & 0.06 & 0.0289 & 0.0153 & 0.0079 & 0.0032 & 0.0036 & 0.0015 & 0.0014 & 0.0003 & & 0 & 0.0563 & 0.0563 & 0.5 \\
\hline COS & 0 & 0 & 0 & 0.0289 & 0.025 & 0.0105 & 0 & 0.0158 & 0 & 0 & 0 & 0 & & 0 & 0 & 0 \\
\hline M-MERC & 0 & 0 & 0 & 0.0592 & 0.0694 & 0.0657 & 0.0399 & 0.072 & 0.0594 & 0.0593 & 0.058 & 0.0563 & 0 & & 0 & 0 \\
\hline E-MERC & 0 & 0 & 0 & 0.0592 & 0.0608 & 0.0564 & 0.0602 & 0.0369 & 0.0594 & 0.0593 & 0.058 & 0.0563 & 0 & 0 & & 0 \\
\hline $\mathrm{H}_{2} \mathrm{O}$ & -0.3156 & 0.0445 & 0.0819 & 0.5 & 0.5 & 0.5 & 0.5 & 0.5 & 0.5 & 0.48 & 0.5 & 0.5 & 0 & 0 & 0 & \\
\hline
\end{tabular}


Table A2. Details of validation of the different thermodynamic packages in simulation of the existing NGL plant.

\begin{tabular}{lccccccc}
\hline Parameter & Current value & PR & Error $(\%)$ & Mod. PR & Error $(\%)$ & SRK & Error $(\%)$ \\
\hline Temp. of $52\left({ }^{\circ} \mathrm{C}\right)$ & -35.00 & -36.30 & 3.70 & -36.02 & 2.91 & -35.28 & 0.79 \\
Temp. of $54\left({ }^{\circ} \mathrm{C}\right)$ & -66.80 & -66.96 & 0.24 & -66.70 & 0.15 & -65.94 & 1.29 \\
Temp. of $56\left({ }^{\circ} \mathrm{C}\right)$ & 16.20 & 17.31 & 6.87 & 16.82 & 3.83 & 16.34 & 0.86 \\
Temp. of $58\left({ }^{\circ} \mathrm{C}\right)$ & 36.30 & 37.71 & 3.89 & 37.88 & 4.35 & 36.28 & 0.04 \\
Temp. of $63\left({ }^{\circ} \mathrm{C}\right)$ & 8.70 & 7.69 & 11.65 & 7.74 & 11.06 & 7.30 & 16.06 \\
Temp. of $64\left({ }^{\circ} \mathrm{C}\right)$ & 104.60 & 104.50 & 0.10 & 104.61 & 0.01 & 104.59 & 0.01 \\
Temp. of $86\left({ }^{\circ} \mathrm{C}\right)$ & 89.50 & 91.62 & 2.37 & 91.70 & 2.46 & 90.70 & 1.45 \\
Temp. of $91\left({ }^{\circ} \mathrm{C}\right)$ & 60.00 & 60.36 & 0.60 & 60.34 & 0.57 & 59.96 & 0.07 \\
Temp. of $248\left({ }^{\circ} \mathrm{C}\right)$ & -87.20 & -87.10 & 0.12 & -87.13 & 0.08 & -86.63 & 0.65 \\
Flow of $58\left(\mathrm{kmol} \mathrm{hr}{ }^{-1}\right)$ & 1729 & 1709 & 1.19 & 1695 & 1.92 & 1775 & 2.62 \\
Flow of $63\left(\mathrm{kmol} \mathrm{hr}{ }^{-1}\right)$ & 954 & 924 & 3.15 & 909 & 4.63 & 989 & 3.74 \\
Flow of $91\left(\mathrm{kmol} \mathrm{hr}{ }^{-1}\right)$ & 920 & 938 & 2.02 & 939 & 2.08 & 938 & 1.98 \\
C ${ }_{5}^{+}$content of $89(\%$ mol $)$ & $\leq 0.0032$ & 0.0120 & 275.72 & 0.0019 & 0.00 & 0.0119 & 272.79 \\
Deethanizer cond. duty $(\mathrm{kW})$ & 4020 & 3585 & 10.83 & 3548 & 11.47 & 3545 & 11.83 \\
Depropanizer cond. duty $(\mathrm{kW})$ & 11980 & 11744 & 1.97 & 11759 & 1.85 & 11805 & 1.46 \\
Debutanizer cond. duty $(\mathrm{kW})$ & 6500 & 5532 & 14.89 & 6338 & 2.49 & 5546 & 14.68 \\
Demethanizer reb. duty $(\mathrm{kW})$ & 3450 & 3648 & 5.75 & 3568 & 3.43 & 3016 & 12.57 \\
Deethanizer reb. duty $(\mathrm{kW})$ & 7670 & 7253 & 5.43 & 7182 & 6.36 & 7499 & 2.23 \\
Depropanizer reb. duty $(\mathrm{kW})$ & 11430 & 11093 & 2.95 & 11112 & 2.78 & 11116 & 2.74 \\
Debutanizer reb. duty $(\mathrm{kW})$ & 4695 & 3878 & 17.41 & 4686 & 0.19 & 3867 & 17.64 \\
Average error $(\%)$ & & & 18.54 & & 3.13 & & 18.28 \\
\hline
\end{tabular}


Table A3. The amounts of $a_{i}$ in equation (19).

\begin{tabular}{|c|c|c|c|c|c|c|c|c|c|c|c|}
\hline \multirow[t]{2}{*}{$i$} & \multirow[t]{2}{*}{$f_{i}(X)$} & \multicolumn{2}{|l|}{$a_{i}$} & \multirow[t]{2}{*}{$i$} & \multirow[t]{2}{*}{$f_{i}(X)$} & \multicolumn{2}{|l|}{$a_{i}$} & \multirow[t]{2}{*}{$i$} & \multirow[t]{2}{*}{$f_{i}(X)$} & \multicolumn{2}{|l|}{$a_{i}$} \\
\hline & & Actual & Coded & & & Actual & $\overline{\text { Coded }}$ & & & Actual & Coded \\
\hline 1 & $x_{1}$ & -5682.3 & 464.6 & 40 & $x_{1} x_{6} x_{7}$ & -1.9 & 0.6 & 79 & $x_{1} x_{4} x_{6} x_{7}$ & 0.1 & 29.8 \\
\hline 2 & $x_{2}$ & -2305.7 & 606.2 & 41 & $x_{1} x_{6} x_{8}$ & 3.8 & 0.1 & 80 & $x_{1} x_{4} x_{6} x_{8}$ & -0.3 & -22.1 \\
\hline 3 & $x_{3}$ & 748.7 & 565.2 & 42 & $x_{2} x_{3} x_{5}$ & 0.2 & 24.3 & 81 & $x_{2} x_{3} x_{5} x_{8}$ & $-5.2 \times 10^{-3}$ & -3.2 \\
\hline 4 & $x_{4}$ & -5421.3 & 596.6 & 43 & $x_{2} x_{3} x_{6}$ & -33.8 & 57.5 & 82 & $x_{2} x_{3} x_{6} x_{7}$ & -0.1 & -16.5 \\
\hline 5 & $x_{1} x_{2}$ & 181.1 & 63.3 & 44 & $x_{2} x_{3} x_{7}$ & 0.2 & 11.6 & 83 & $x_{3} x_{4} x_{5} x_{7}$ & $1.0 \times 10^{-2}$ & 25.5 \\
\hline 6 & $x_{1} x_{3}$ & -47.4 & 308.1 & 45 & $x_{2} x_{3} x_{8}$ & 0.2 & -4.7 & 84 & $x_{1} x_{2} x_{6}^{2}$ & 13.6 & 135.2 \\
\hline 7 & $x_{1} x_{4}$ & 117.0 & 250.1 & 46 & $x_{2} x_{4} x_{5}$ & -3.8 & -2.2 & 85 & $x_{1} x_{4} x_{5}^{2}$ & 0.1 & 52.8 \\
\hline 8 & $x_{1} x_{5}$ & 98.6 & -54.8 & 47 & $x_{2} x_{4} x_{6}$ & -27.6 & 57.1 & 86 & $x_{2} x_{3} x_{6}^{2}$ & 6.9 & 68.9 \\
\hline 9 & $x_{1} x_{6}$ & 3442.2 & -13.0 & 48 & $x_{2} x_{5} x_{6}$ & -4.2 & -20.0 & 87 & $x_{2} x_{4} x_{5}^{2}$ & $3.9 \times 10^{-2}$ & 28.4 \\
\hline 10 & $x_{1} x_{7}$ & 0.2 & -1.5 & 49 & $x_{2} x_{5} x_{7}$ & $4.3 \times 10^{-2}$ & 0 & 88 & $x_{2} x_{4} x_{6}^{2}$ & 5.2 & 51.5 \\
\hline 11 & $x_{1} x_{8}$ & -7.9 & -6.3 & 50 & $x_{2} x_{5} x_{8}$ & 0.1 & -1.1 & & & & \\
\hline 12 & $x_{2} x_{3}$ & 27.7 & -8.6 & 51 & $x_{2} x_{6} x_{7}$ & 1.1 & -3.4 & & & & \\
\hline 13 & $x_{2} x_{4}$ & 126.8 & 5.5 & 52 & $x_{2} x_{6} x_{8}$ & -0.3 & 0 & & & & \\
\hline 14 & $x_{2} x_{5}$ & 25.9 & 14.3 & 53 & $x_{3} x_{4} x_{5}$ & -0.7 & -2.8 & & & & \\
\hline 15 & $x_{2} x_{6}$ & 1404.7 & -35.1 & 54 & $x_{3} x_{4} x_{6}$ & 1.2 & 34.0 & & & & \\
\hline 16 & $x_{2} x_{7}$ & -5.3 & -1.4 & 55 & $x_{3} x_{4} x_{7}$ & -0.5 & 3.1 & & & & \\
\hline 17 & $x_{2} x_{8}$ & -2.8 & -0.9 & 56 & $x_{3} x_{5} x_{6}$ & 3.5 & 9.8 & & & & \\
\hline 18 & $x_{3} x_{4}$ & 29.7 & 5.0 & 57 & $x_{3} x_{5} x_{7}$ & -0.1 & -0.7 & & & & \\
\hline 19 & $x_{3} x_{5}$ & -41.4 & -32.6 & 58 & $x_{3} x_{5} x_{8}$ & 0.2 & -0.5 & & & & \\
\hline 20 & $x_{3} x_{6}$ & 405.4 & -7.1 & 59 & $x_{3} x_{6} x_{7}$ & 1.8 & -2.9 & & & & \\
\hline 21 & $x_{3} x_{7}$ & -1.2 & -9.7 & 60 & $x_{3} x_{6} x_{8}$ & -0.3 & 0 & & & & \\
\hline 22 & $x_{3} x_{8}$ & -5.7 & -1.2 & 61 & $x_{4} x_{5} x_{6}$ & 3.3 & 7.9 & & & & \\
\hline 23 & $x_{4} x_{5}$ & 205.1 & -24.7 & 62 & $x_{4} x_{5} x_{7}$ & -0.3 & -6.3 & & & & \\
\hline 24 & $x_{4} x_{6}$ & 47.1 & -10.6 & 63 & $x_{4} x_{5} x_{8}$ & -0.1 & 0 & & & & \\
\hline 25 & $x_{4} x_{7}$ & 18.2 & -8.7 & 64 & $x_{4} x_{6} x_{7}$ & -1.2 & 1.0 & & & & \\
\hline 26 & $x_{4} x_{8}$ & -3.6 & -2.0 & 65 & $x_{4} x_{6} x_{8}$ & 2.0 & 3.1 & & & & \\
\hline 27 & $x_{1} x_{2} x_{5}$ & -1.8 & 87.5 & 66 & $x_{1} x_{5}^{2}$ & -0.6 & 4.2 & & & & \\
\hline 28 & $x_{1} x_{2} x_{6}$ & -108.1 & 183.3 & 67 & $x_{1} x_{6}{ }^{2}$ & -397.2 & -1.9 & & & & \\
\hline 29 & $x_{1} x_{3} x_{5}$ & 0.8 & 198.5 & 68 & $x_{1} x_{7}^{2}$ & $1.0 \times 10^{-3}$ & 0 & & & & \\
\hline 30 & $x_{1} x_{3} x_{6}$ & 3.7 & 104.0 & 69 & $x_{2} x_{5}^{2}$ & -0.2 & 1.7 & & & & \\
\hline 31 & $x_{1} x_{3} x_{7}$ & $4.3 \times 10^{-2}$ & 34.5 & 70 & $x_{2} x_{6}{ }^{2}$ & -232.7 & -57.1 & & & & \\
\hline 32 & $x_{1} x_{3} x_{8}$ & $-4.6 \times 10^{-2}$ & -9.4 & 71 & $x_{2} x_{7}^{2}$ & $1.0 \times 10^{-3}$ & 0 & & & & \\
\hline 33 & $x_{1} x_{4} x_{5}$ & -6.3 & 164.1 & 72 & $x_{3} x_{5}^{2}$ & 0.3 & 0 & & & & \\
\hline 34 & $x_{1} x_{4} x_{6}$ & 4.8 & 88.5 & 73 & $x_{3} x_{6}{ }^{2}$ & -128.9 & -15.3 & & & & \\
\hline 35 & $x_{1} x_{4} x_{7}$ & -0.2 & 62.7 & 74 & $x_{3} x_{7}^{2}$ & $1.0 \times 10^{-3}$ & 0 & & & & \\
\hline 36 & $x_{1} x_{4} x_{8}$ & 0.9 & 11.9 & 75 & $x_{4} x_{5}^{2}$ & -2.0 & -18.9 & & & & \\
\hline 37 & $x_{1} x_{5} x_{6}$ & -31.5 & -15.2 & 76 & $x_{4} x_{6}{ }^{2}$ & -44.7 & -3.5 & & & & \\
\hline 38 & $x_{1} x_{5} x_{7}$ & 0.1 & 6.7 & 77 & $x_{4} x_{7}^{2}$ & $-7.2 \times 10^{-3}$ & -7.5 & & & & \\
\hline 39 & $x_{1} x_{5} x_{8}$ & -0.1 & 0 & 78 & $x_{1} x_{2} x_{5} x_{6}$ & 0.8 & 65.5 & & & & \\
\hline
\end{tabular}


Table A4. Comparison of products and steam consumed of the existing and optimized plants.

\begin{tabular}{lcc}
\hline Parameter & Existing NGL plant & Optimized integrated plant \\
\hline NG $\left(\mathrm{kg} \mathrm{hr}^{-1}\right)$ & 377092 & - \\
Ethane $\left(\mathrm{kg} \mathrm{hr}^{-1}\right)$ & 26135 & 32408 \\
Propane $\left(\mathrm{kg} \mathrm{hr}^{-1}\right)$ & 40917 & 41144 \\
LNG $\left(\mathrm{kg} \mathrm{hr}^{-1}\right)$ & - & 344,217 \\
Ethane $/ \mathrm{Propane} \mathrm{recovery}(\% \mathrm{~mol})_{\text {Consumed steam }\left(\mathrm{klb} \mathrm{hr}^{-1}\right)}^{64.72 / 94.39}$ & $80.11 / 94.92$ \\
AR $\left(\$\right.$ min $\left.^{-1}\right)$ & 107.57 & 109.09 \\
\hline
\end{tabular}

Table A5. Electrical power consumed of added equipments at the optimal conditions.

\begin{tabular}{lccccc}
\hline Equipment & Power $^{\mathrm{a}}(\mathrm{kW})$ & Equipment & Power $(\mathrm{kW})$ & Equipment & Power $(\mathrm{kW})$ \\
\hline P-WC1 & 12.72 & $\mathrm{~K}-1$ & 3368.49 & $\mathrm{~K}-5^{\mathrm{b}}$ & -702.79 \\
P-WC2 & 20.17 & $\mathrm{~K}-2$ & 9623.12 & $106-\mathrm{K} 101^{\mathrm{c}}$ & 19228.52 \\
P-WC3 & 24.86 & $\mathrm{~K}-3$ & 43122.26 & Total AC & 212.61 \\
P-WC4 & 820.23 & $\mathrm{~K}-4$ & 24567.52 & $105-\mathrm{P}-101^{\mathrm{d}}$ & 25.69 \\
\hline
\end{tabular}

${ }^{a}$ Isentropic efficiency of pumps and compressors is equal to $75 \%$.

${ }^{\mathrm{b}}$ Current 106-K101 is replaced to this equipment and the presented power is the difference of them.

${ }^{\mathrm{c}}$ New equipment that is replaced to current 106-K101.

${ }^{\mathrm{d}}$ New equipment that is replaced to current 105-P101 and the presented power is the difference of them.

Table A6. Bare-module cost of added and changed equipments at the optimal conditions.

\begin{tabular}{|c|c|c|c|c|c|}
\hline Equipment & $\mathrm{BM}(\$)$ & Equipment & $\mathrm{BM}(\$)$ & Equipment & $\mathrm{BM}(\$)$ \\
\hline $\mathrm{AC}-1$ & 1393200 & D-3 & 299800 & 106-K101 (new) & 10146300 \\
\hline $\mathrm{AC}-2$ & 2765800 & D-4 & 220800 & E-1 & 2492300 \\
\hline $\mathrm{AC}-3$ & 2199800 & D-5 & 1366300 & E-2 & 3158400 \\
\hline $\mathrm{AC}-4$ & 3561600 & D-6 & 541800 & E-3 & 2795400 \\
\hline WC-1 & 285000 & D-7 & 867700 & E-4 & 727600 \\
\hline WC-2 & 269400 & $\mathrm{~K}-1$ & 15615200 & E-5 & 1042800 \\
\hline WC-3 & 383200 & $\mathrm{~K}-2$ & 19923500 & E-6 & 1134100 \\
\hline WC-4 & 7902700 & $\mathrm{~K}-3 \mathrm{~A}$ & 28863100 & 105-P-101 (new) & 132500 \\
\hline D-1 & 531500 & $\mathrm{~K}-3 \mathrm{~B}$ & 28863100 & MPHX-1 & 4203400 \\
\hline $\mathrm{D}-2$ & 417000 & $\mathrm{~K}-4$ & 12406300 & MPHX-2 & 1410800 \\
\hline
\end{tabular}


Table A7. Overall geometry of MPHX-1\&2 at the optimal conditions.

\begin{tabular}{lcc}
\hline Specification & MPHX-1 & MPHX-2 \\
\hline Number of exchangers in parallel & 40 & 6 \\
Number of layers per exchanger & $(109,8,11,64)$ & $87,17,54)$ \\
Core length (m) & 7.6998 & 4.2938 \\
Core width (m) & 0.5983 & 0.5986 \\
Core depth (m) & 1.7163 & 0.7818 \\
Distributor length - end A (m) & 0.4419 & 0.2369 \\
Main heat transfer length (m) & 6.9634 & 3.8439 \\
Distributor length - end B (m) & 0.2945 & 0.213 \\
Internal (effective) width (m) & 0.5753 & 0.5756 \\
Side bar width (m) & 0.0115 & 0.0115 \\
Parting sheet thickness (m) & 0.0025 & 0.0025 \\
Cap sheet thickness (m) & 0.005 & 0.005 \\
Exchanger metal & Aluminum & Aluminum \\
Exchanger weight - empty (kg) & 521480.1 & 19857 \\
Exchanger weight - operating (kg) & 593582.5 & 22882.1 \\
\hline
\end{tabular}

